\author{
Universidade de São Paulo \\ Instituto de Astronomia, Geofísica e Ciências Atmosféricas \\ Departamento de Geofísica
}

Estevão Vasconcello Campos Tadeu

\title{
MODELO DE VELOCIDADE DA ONDA S (1D) PARA A LITOSFERA DA BACIA DO PANTANAL
}

São Paulo 

Estevão Vasconcello Campos Tadeu

\section{MODELO DE VELOCIDADE DA ONDA S (1D) PARA A LITOSFERA DA BACIA DO PANTANAL}

Dissertação apresentada ao Departamento de Geofísica do Instituto de Astronomia, Geofísica e Ciências Atmosféricas da Universidade de São Paulo como requisito parcial para a obtenção do título de Mestre em Ciências.

Área de Concentração: Geofísica Orientador: Prof. Dr. Marcelo Assumpção Versão Corrigida. O original encontra-se disponível na Unidade.

São Paulo 

A minha Família! 



\section{Agradecimentos}

À minha família que embora distante, sempre tentaram estar presentes e apoiando.

Às pessoas que me receberam logo quando cheguei ao IAG, sendo elas Igor Eufrásio e Pedro Chibane.

Ao grupo de sismologia pelo apoio, informações e experiências.

À Carol Rivadeneyra, Israel Dragone, Bruna Chagas, Leonardo Fabricius, Jaime Convers, Fábio Dias e Taghi Shirzad pelas dicas em disciplinas, trabalhos e na dissertação.

Ao meu orientador Professor Dr. Marcelo Assumpção pelo conhecimento e pela paciência para comigo, foram dois anos bem produtivos.

Ao meu relator Professor Dr. Carlos Chaves, pelas sugestões, paciência e por sempre me receber.

À Coordenação de Aperfeiçoamento de Pessoal de Nível Superior (CAPES) pela concessão da bolsa de estudos.

Ao Professor Dr. Marcelo Bianchi, pelas sugestões, conselhos.

Ao Bruno Collaço pelo apoio, opiniões, sugestões e pelos board games de sexta-feira.

À minha namorada Cinthia Ide pela paciência, compreensão e carinho. 

"Não existe triunfo sem perda, não há vitória sem sofrimento, não há liberdade sem sacrifício."

J.R.R. Tolkien 



\section{Resumo}

A Bacia Sedimentar do Pantanal é sismicamente ativa, com terremotos registrados de magnitude até $m_{b} 5,4$. O manto superior desta região apresenta uma queda de velocidade das ondas sísmicas P e S, em comparação com as regiões vizinhas na América do Sul (Assumpção et al., 2004) (Feng et al., 2007). Para entender melhor a causa dessa anomalia de baixa velocidade na Bacia do Pantanal, analisamos as curvas de dispersão de ondas de superfície de terremotos com magnitudes maiores ou iguais a 5,5, com diferentes distribuições azimutais. Medimos as velocidades de fase e de grupo para o modo de vibração fundamental e primeiro modo superior das ondas Rayleigh e fundamental para a Love. Aplicamos a Técnica de Filtragem Múltipla e o método de empilhamento para obter as velocidades de grupo e de fase dessas ondas. Isso nos permitiu obter modelos de velocidade da onda S (1D) para a Bacia do Pantanal. As velocidades de fase e de grupo foram invertidas usando o método linear de Surf96, resultando em seis modelos de velocidade para a Bacia do Pantanal. Dois modelos exibem velocidades mais altas do que as do IASP91 em $110 \mathrm{~km}$ e $150 \mathrm{~km}$ de profundidade. Os outros quatro têm velocidades baixas nas regiões entre 110 km e 120 km, assim como em $150 \mathrm{~km}$ de profundidade. Isto provavelmente evidência uma litosfera mais fina na Bacia do Pantanal, como proposto por Assumpção et al. (2004). 



\section{Abstract}

The Pantanal Sedimentary Basin is seismically active, with recorded earthquakes of magnitudes up to $m_{b} 5.4$. The upper mantle of this region exhibits a relatively low $\mathrm{P}$ and S seismic wave velocity, compared to neighboring regions in South America Assumpção et al., 2004) (Feng et al., 2007). To better understand the cause of this velocity anomaly in the Pantanal Basin, we analyzed surface wave dispersion curves of earthquakes with magnitudes greater than or equal to 5.5, with different azimuthal distributions. We measure phase and group velocities for the fundamental and first superior vibration modes for Rayleigh surface waves and the fundamental mode of Love wave dispersion curves. We apply the Multiple Filtering Technique and stacking methods to obtain the group and phase velocities of the Rayleigh and Love waves. This allowed us to obtain S wave velocity (1D) models for the Pantanal Basin. The group and phase velocities were inverted using the linear method of Surf96, resulting in six S-wave velocity models for the Pantanal Basin. Two models exhibit velocities higher than those in IASP91 at $110 \mathrm{~km}$ and $150 \mathrm{~km}$ depth. The other four have low-velocities in a region between $110 \mathrm{~km}$ and $120 \mathrm{~km}$, as well as at $150 \mathrm{~km}$ depth. This most likely evidences a thinner lithosphere in the Pantanal Basin, as proposed by Assumpção et al. (2004). 



\section{Lista de Figuras}

1.1 Localização da Bacia do Pantanal. (a) Mapa geológico. (b) Modelo digital de elevação. Imagem de Assine et al. (2015) . . . . . . . . . . . . . . .

1.2 Províncias geológicas, os círculos em vermelho representam os sismos, cujas magnitudes variam de 3,5 a 6,2. As barras em azul, verde e laranja são estimativas das direções de tensão horizontal máxima (SHmax) dos mecanismos de falha inversa, transcorrente e normal, respectivamente (o tamanho de cada barra denota a qualidade dos dados). As barras em azul que estão abertas representam dados hidráulicos. As áreas em rosa são os crátons arqueanos e paleoproterozóicos, os em cinza são neoproterozóicos, paleozóicos e os em amarelo são as principais bacias fanerozóicas $(\mathrm{Pt}=$ bacia do Pantanal). TBL é a sigla do Lineamento Transbrasiliano. Na Província do Tocantins, $\mathrm{AFB}=$ cinturão do Araguaia, $\mathrm{MA}=$ Arco Magmático NeoProterozóico e GM = Maciço Arqueano de Goiás. Imagem retirada de (Assumpção e Sacek, 2013).

1.3 Um modelo possível para o que ocorre em regiões de maior sismicidade, o qual apresenta zonas de baixa velocidade para as ondas sísmicas, podendo estar associado ao afinamento litosférico e como consequência soerguimento da astenosfera. Imagem retirada de (Assumpção et al., 2004). . . . . . . . .

1.4 Anomalias da onda S em $100 \mathrm{~km}$ de profundidade, obtidas com dispersão das ondas de superfície, imagem retirada de (Feng et al., 2007). A região de anomalia negativa da bacia se situa entre $15^{\circ}$ a $20^{\circ} \mathrm{S}$ e a $55^{\circ}$ a $60^{\circ} \mathrm{W}$. Pt $=$ Pantanal. TBL: Lineamento Transbrasiliano. . . . . . . . . . . . . . . . 
1.5 Valores de Te (espessura elástica efetiva da litosfera) para a América do Sul. Imagem retirada Pérez-Gussinyé et al. (2007). . . . . . . . . . . . . 27

2.1 Propagação e movimento de partícula das Ondas Rayleigh e Love. Imagem adaptada de Feng $(2004)$. . . . . . . . . . . . . . . . . . . 30

2.2 Modelos 1D e 3D de Oscilação livre. Imagens adaptadas de Freedman et al. (2009) e OpenCourseWare $(2008)$. . . . . . . . . . . . . . . . . .

2.3 Núcleos de sensibilidade das ondas Love à esquerda e à direita Rayleigh, seus períodos variam de 10 a 100s para um perfil de velocidade da crosta continental. Retirado de Pasyanos $(2005)$. . . . . . . . . . . . . . . .

2.4 Fluxograma de processamento, dividido em seis etapas, sendo elas preparação individual, Técnica de Filtragem Múltipla, empilhamento, obetenção das velocidades de grupo do arranjo, controle de qualidade e inversão das velocidades encontradas. . . . . . . . . . . . . . . .

2.5 Sismograma original, evento com epicentro no Chile de magnitude $m_{b} 5,9$. O símbolo O corresponde ao tempo de origem, IPU0 corresponde a primeira chegada da onda P e ISU0 corresponde a primeira chegada da onda S. O eixo x representa o tempo em segundos e o eixo y esta em contagem. . . .

2.6 Sismograma em deslocamento, decimado e rotacionado, evento com epicentro no Chile de magnitude $m_{b} 5,9$. O símbolo $\mathrm{O}$ corresponde tempo de origem, IPU0 corresponde a primeira chegada da onda P e ISU0 corresponde a primeira chegada da onda S. O eixo x representa o tempo em segundos e

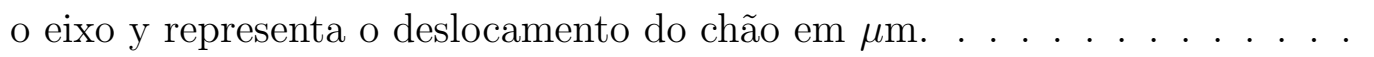

2.7 Curvas de dispersão de velocidade de grupo da onda Rayleigh de um evento. O eixo x representa o período, e o y a velocidade. Nesta envoltória é possível observar o sismograma completo, contendo modo fundamental de vibração, sua envoltória inicia com período de 11 a 120 segundos e velocidade de 3.5 a $3.8 \mathrm{~km} / \mathrm{s}$. Os quadrados em preto representam os pontos mais confiáveis na curva de dispersão, os círculos e triângulos são ruídos. A cor vermelha representa a região com maior energia na envoltória. . . . . . . . . . . 
2.8 Curvas de dispersão, envoltória já filtrada, $\alpha=50$, para o modo fundamental da onda Rayleigh do o evento da figura 2.7. O eixo x representa o período, e o y a velocidade. Nesta envoltória o modo fundamental com período de 11 a 120 segundos e velocidade de 3.5 a $3.8 \mathrm{~km} / \mathrm{s}$. Os quadrados em preto representam os pontos mais confiáveis na curva de dispersão, os círculos e triângulos são ruídos. Pode-se perceber que área grande quantidades de pontos com ruído em torno de $3,00 \mathrm{~km} / \mathrm{s}$ foi descartada após a passagem da MFT.

2.9 Estações Sismográficas instaladas na área de estudo, inseridas em um mapa de topografia. As estações em azul são pertencentes à rede BL, as em roxo pertencem à rede temporária XC e única em preto, pertence à BR. . . . . . .

2.10 Gráfico para a obtenção da velocidade de grupo média em cada período, no arranjo de estações da área de estudo. Onde velocidade média é o ajuste de reta entre os pontos de cada período.

2.11 Empilhamento dos sismogramas filtrados. Calculo das velocidades de fase entre as estações que foram utilizadas. No eixo x (período), o primeiro marcador representa 21 e o último 47 segundos. No eixo y está representado a velocidade de fase em torno de 3.60 a $3,8 \mathrm{~km} / \mathrm{s}$. Os ponto em preto representam os pontos de dispersão. A cor vermelha representa a região com maior energia na envoltória.

2.12 Curva de dispersão de baixa qualidade. À esquerda temos a velocidade de fase para o primeiro modo superior da onda Rayleigh. À direita temos as curvas de U em cada estação observadas em cada estação. . . . . . . . . .

2.13 Curvas de dispersão com boa qualidade. À esquerda temos a velocidade de fase para o primeiro modo superior da onda Rayleigh. À direita temos as curvas de U em cada estação observadas em cada estação. . . . . . . . . . 41

2.14 Epicentros dos eventos trabalhados. Estrelas em vermelho são os eventos e a área circulada em azul é a Bacia do Pantanal.

2.15 Todas as curvas de dispersão de Velocidade de fase para onda Rayleigh, cada cor representa uma evento, sendo a numeração de cada evento igual á Tabela 2.2. . . . . . . . . . . . . . . . . . . 
2.16 Curvas de C (km/s) para o primeiro modo de vibração da Rayleigh. Cada cor representa a numeração de cada evento que foi possível obter as velocidade, de acordo com a Tabela $2.2 \ldots \ldots \ldots$. . . . . . . . . . .

2.17 Curvas de U (km/s) do arranjo. Cada cor representa a numeração de cada evento que foi possível obter as curvas velocidade de grupo da Rayleigh, de

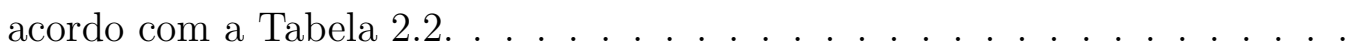

2.18 Curvas de C $(\mathrm{km} / \mathrm{s})$ para o modo fundamental para onda Love. Cada cor representa a numeração de cada evento que foi possível obter as velocidade, de acordo com a Tabela II.O eixo y é a velocide de fase observada e o x período observado.

2.19 Curvas médias C $(\mathrm{km} / \mathrm{s})$ e $\mathrm{U}(\mathrm{km} / \mathrm{s})$ para os modos da onda Rayleigh e Love. O eixo y é a velociade de fase observada e o x período observado. . .

3.1 À esquerda está o primeiro modelo inicial para a Love em azul e o modelo final em vermelho, após 40 iterações e o modelo IASP91 em preto, usado para comparação. À direita temos o ajuste da curva de dispersão de C $(\mathrm{km} / \mathrm{s})$. Onde os círculos em azul representam o dado observado e a reta em vermelho o dado calculado. . . . . . . . . . . . . . . . . . . . .

3.2 À esquerda temos o segundo modelo inicial da Love em azul e o modelo final em vermelho, após 18 iterações e o modelo IASP91 em preto, usado para comparação. À direita temos o ajuste da curva de dispersão de C. Onde os círculos em azul representam o dado observado e a reta em vermelho o dado calculado.

3.3 À esquerda temos o terceiro modelo inicial da Love em azul e o modelo final em vermelho, após 40 iterações e o modelo IASP91 em preto, usado para comparação. À direita temos o ajuste da curva de dispersão de C. Onde os círculos em azul representam o dado observado e a reta em vermelho o dado calculado. 
3.4 A: Primeiro modelo inicial da Rayleigh em azul e o modelo final em vermelho, após 40 iterações e o modelo IASP91 em preto, usado para comparação, desvio padrão de $\pm 0,034 \mathrm{~km} / \mathrm{s}$. B: ajuste das curvas de dispersão de $\mathrm{C}$ e U $(\mathrm{km} / \mathrm{s})$. Onde os círculos em verde representam C (observada) e a reta em preto C (calculada), do modo fundamental. Os pontos em azul são C (observada) para o primeiro modo de vibração, e a reta em vermelho C (calculada). Já os círculos em amarelo representam U (observada) e a reta em magenta U (calculada), do modo fundamental. C e D: Núcleos de sensibilidade de U e C para a onda Rayleigh. . . . . . . . . . . . . . . . . . . . .

3.5 A: Segundo modelo inicial da Rayleigh em azul e o modelo final em vermelho, após 18 iterações e o modelo IASP91 em preto, usado para comparação, desvio padrão de \pm 0,018. B: ajuste das curvas de dispersão de $\mathrm{C}$ e U (km/s). Onde os círculos em verde representam C (observada) e a reta em preto $\mathrm{C}$ (calculada), do modo fundamental. Os pontos em azul são C (observada) para o primeiro modo de vibração, e a reta em vermelho C (calculada). Já os círculos em amarelo representam U (observada) e a reta em magenta U (calculada), do modo fundamental. C e D: Núcelos de sensibilidade de U e C para a onda Rayleigh. . . . . . . . . . . . . . . . . . .

3.6 A: Terceiro modelo inicial da Rayleigh em azul e o modelo final em vermelho, após 40 iterações e o modelo IASP91 em preto, usado para comparação, desvio padrão de $\pm 0,059 \mathrm{~km} / \mathrm{s}$. B: ajuste das curvas de dispersão de C e $\mathrm{U}(\mathrm{km} / \mathrm{s})$. Onde os círculos em verde representam C (observada) e a reta em preto $\mathrm{C}$ (calculada), do modo fundamental. Os pontos em azul são C (observada) para o primeiro modo de vibração, e a reta em vermelho C (calculada). Já os círculos em amarelo representam U (observada) e a reta em magenta $\mathrm{U}$ (calculada), do modo fundamental. C e D: Núcelos de sensibilidade de U e C para a onda Rayleigh. . . . . . . . . . . . . . . .

3.7 Comparação entre os modelos finais da Rayleigh e da Love. A Descontinuidade de Mohorovicic esta entre 35 a $40 \mathrm{~km}$ e o Limite entre a Litsofera e Astenosfera inicia-se entre $110 \mathrm{~km}$. 
3.8 Mapa atualizado da espessura da crosta na América do Sul. Círculos vermelhos são dados de Assumpção et al. (2013). Os círculos brancos são os dados atuais, proveniente das análises das redes XC e RSBR. Imagem retirada de Rivadeneyra-Vera et al. (2019). . . . . . . . . . . . . 55

3.9 Observações geofísicas de alguns métodos utilizados para mensurar o LAB, como por exemplo, mudança na taxa de deformação; aumento na temperatura; região de baixa velocidade para a onda $\mathrm{S}$ (podendo estar relacionado com uma mudança tanto composicional, quanto térmica); alteração na anisotropia; diminuição na resistividade. Imagem retirada de Eaton et al.

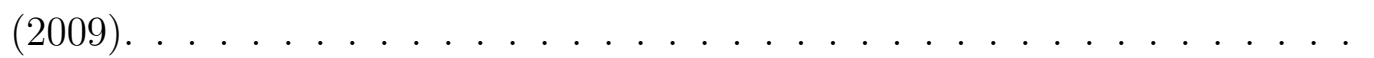

3.10 Modelo de profundidade global para o LAB. Imagem retirada de Plomerová

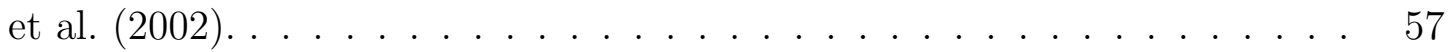

3.11 A: Profundidade da litosfera na BSP. B: Velocidade da onda SV em $150 \mathrm{~km}$. Imagem retirada de CAM2016. . . . . . . . . . . . . . . . 58

3.12 Anomalias da onda S em $150 \mathrm{~km}$ de profundidade, no qual se usou dispersão das ondas de superfície, imagem retirada de Feng et al. (2007). A região de anomalia negativa da bacia se situa entre $15^{\circ}$ a $20^{\circ} \mathrm{S}$ e a $55^{\circ}$ a $60^{\circ} \mathrm{W}$. TBL: Linamento Transbrasiliano. 


\section{Lista de Tabelas}

2.1 Relação entre Faixa Epicentral e $\alpha \ldots \ldots$. . . . . . . . . . . . 35

2.2 Informações dos Eventos . . . . . . . . . . . . . . . . . . . 43

A.1 Estações Utilizadas (Modo Fundamental, Rayleigh) . . . . . . . . . . 70

A.2 Estações Utilizadas (Primeiro Modo Superior, Rayleigh) . . . . . . . . . 7 70

A.3 Estações Utilizadas (Modo Fundamental, Love) . . . . . . . . . . . . . . 70 



\section{Sumário}

1. Introdução . . . . . . . . . . . . . . . . . . . . . 23

2. Teoria e Métodos Empregados . . . . . . . . . . . . . . . . . . . . . . . . . . . 29

2.1 Ondas de Superfície, Dispersão e Modos Normais . . . . . . . . . . . . 29]

2.2 Núcleo de Sensibilidade . . . . . . . . . . . . . . . . . . . . . 32

2.3 Processamento . . . . . . . . . . . . . . . . . . 33

2.3.1 Preparação individual . . . . . . . . . . . . . 33

2.3.2 MFT (Multiple Filtering Techniques) e Aplicação . . . . . . . . 35

2.3.3 Velocidade de Grupo do Arranjo de Estações . . . . . . . . . . . . . . 37

2.3.4 Empilhamento dos Sismogramas Filtrados . . . . . . . . . . . 38

2.3.5 Controle de Qualidade . . . . . . . . . . . . . . . . 40

2.3.6 Inversão das Velocidades de C e U do Arranjo . . . . . . . . . . . . 41

2.4 Dados . . . . . . . . . . . . . . . . . . . . 42

3. Resultados e Discussões . . . . . . . . . . . . . . . . . . . . . . . . 49

3.1 Inversões Para Onda Love . . . . . . . . . . . . . . . . . . . . . . . . . 49

3.1.1 Modelo I . . . . . . . . . . . . . . . . . . . . 49

3.1 .2 Modelo II . . . . . . . . . . . . . . . . . . . . . . . . 49

3.1 .3 Modelo III . . . . . . . . . . . . . . . . . . . . . . . 51

3.2 Inversões Para Onda Rayleigh . . . . . . . . . . . . . . . . . . 51

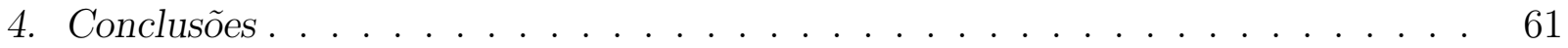

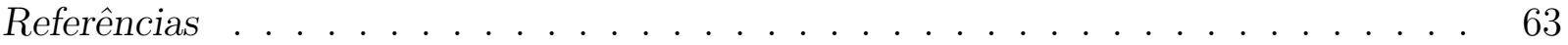


A. Estações Utilizadas Por Evento . . . . . . . . . . . . . . . . . . . . . . 69 
Capítulo 1

\section{Introdução}

A Bacia Sedimentar do Pantanal (BSP) é uma depressão tectônica interior possuindo idade quaternária (Facincani et al., 2011), esta localizada na região centro-oeste do Brasil (Figura 1.1), cobrindo uma área de aproximadamente $135.000 \mathrm{~km}^{2}$ da bacia do Alto Paraguai com altitude de 80 a $180 \mathrm{~m}$ acima do nível do mar (Assine e Soares, 2004).

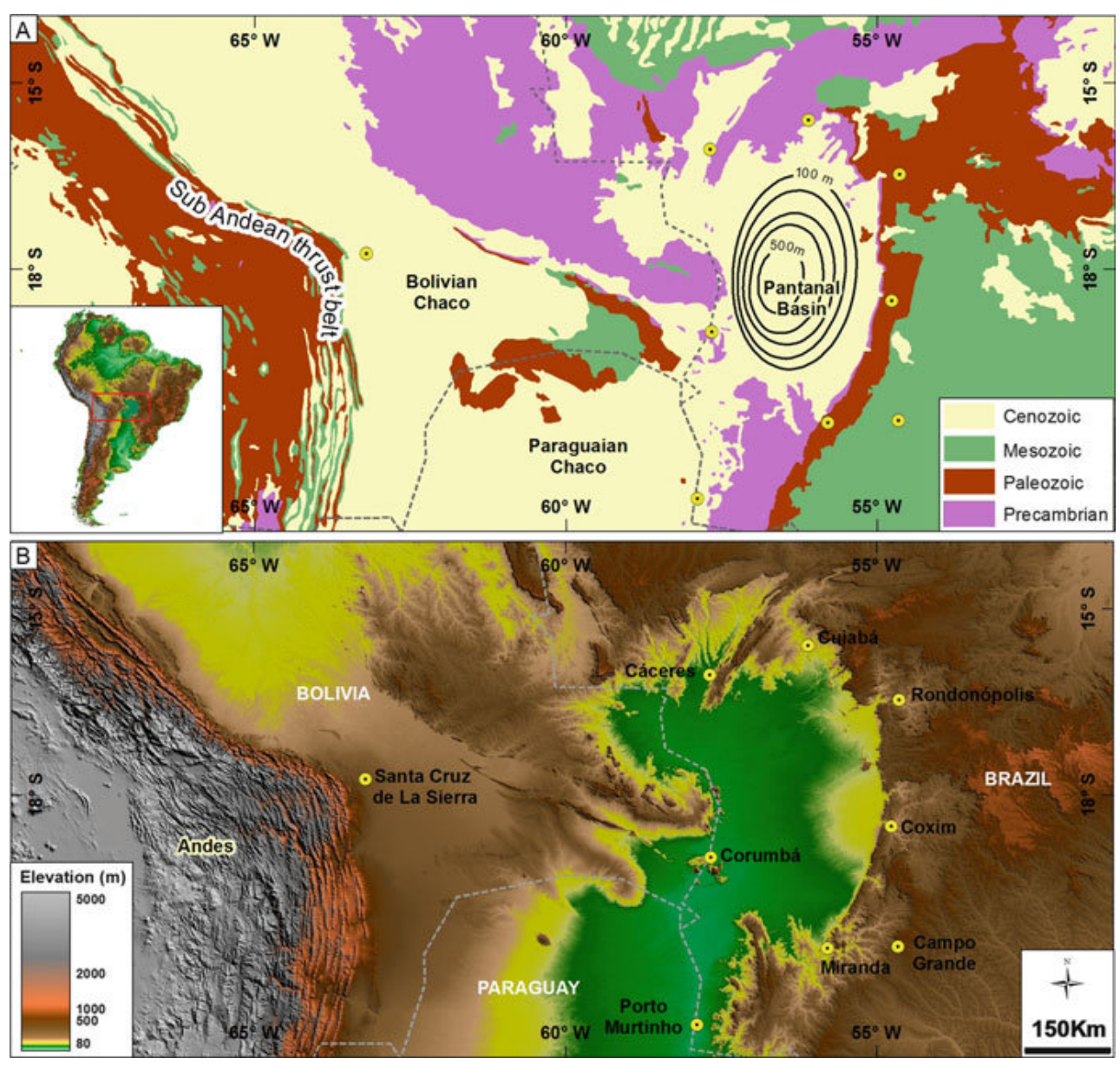

Figura 1.1: Localização da Bacia do Pantanal. (a) Mapa geológico. (b) Modelo digital de elevação. Imagem de Assine et al. (2015) 
A BSP possui uma estratigrafia com afinamento em textura no topo sendo preenchida em boa parte por minerais siliclástico. O seu embasamento é constituído de rochas metamórficas neoproterozóicas dos grupos Cuiabá e Corumbá, como também, em sua porção oriental, rochas sedimentares de unidades paleozóicas da Bacia do Paraná de Almeida et al., 2007). Possui uma espessura de sedimentos de aproximadamente $550 \mathrm{~m}$, mensurados por dados de sísmica. As informações do subsolo estão restritas a 11 poços perfurados em meados de 1960 pela Petrobrás. O mais profundo alcançou 412,5 m da formação do Pantanal (Assine e Soares, 2004).

De acordo com Ussami et al. (1999), seu processo de origem foi uma consequência, da reativação tectônica do forebulge durante o último evento compressivo andino em 2,5 bilhões de anos atrás. O depocentro é paralelo ao alongamento do forebulge (elevação localizada em frente de uma carga na litosfera) e a subsidência foi controlada por falhas.

Na região da BSP ocorreu um dos maiores sismo registrados no Brasil, próximo à cidade de Miranda, em 1964, sendo a magnitude $m_{b}$ 5,4. Outro evento importante ocorreu em Coxim, em junho de 2009, com magnitude de $m_{b}$ 4,8. Estudos realizados por Assumpção e Suárez (1988) e Dias et al. (2016) mostraram que os mecanismos focais de tais eventos estão relacionados a falhas inversas.

Os eventos do Pantanal parecem formar uma zona sísmica em continuação à faixa sísmica de Goiás-Tocantins (Figura 1.2). Há uma linha de epicentros confinada em regiões com anomalias gravitacionais (Ar livre) superiores a -20 mGAl, onde há a formação de uma zona sísmica com aproximadamente $200 \mathrm{~km}$ de largura, podendo ser causada por flexão da litosfera e compressões na crosta superior (Assumpção e Sacek, 2013).

Diversos modelos são propostos para melhor explicar a distribuição de sismicidade em regiões intraplaca. Em geral, os modelos propostos envolvem zonas de fraqueza, concentrações de tensão a partir da variação de densidade lateral, tensões de flexão ou uma combinação de ambos. Contudo, para áreas que apresentam sismos menores, é difícil mensurar e identificar essas zonas de fraqueza. A sismicidade nas áreas central e sudeste do Brasil não são bem distribuídas, como também, não há relação clara com as características geológicas da superfície (Assumpção et al., 2004).

É observado que em regiões de maior sismicidade podem ocorrer zonas de baixa velocidade na litosfera para as ondas $\mathrm{P}$ e $\mathrm{S}$, as quais estariam associadas a um afinamento litosférico e como consequência soerguimento da astenosfera (Figura 1.3). Essa mudança 


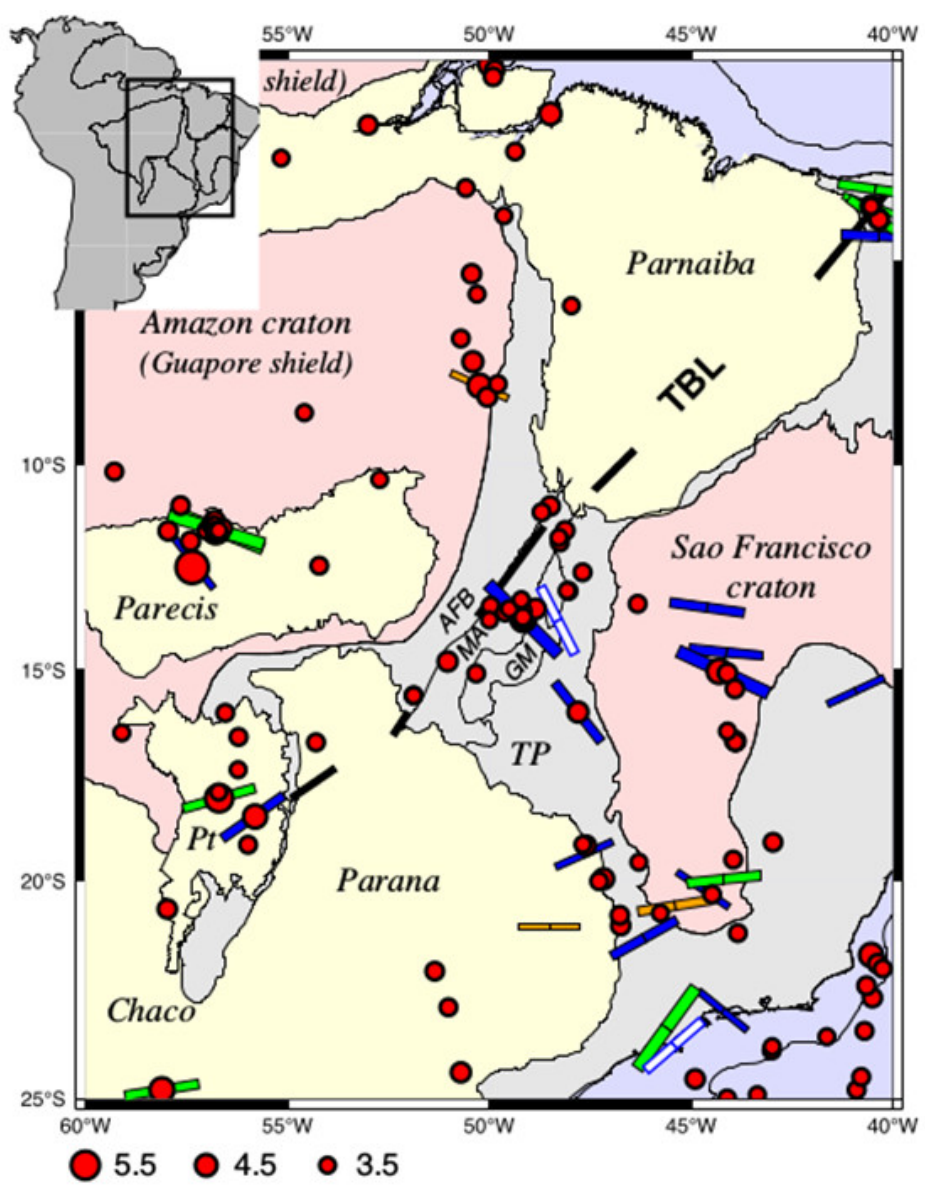

Figura 1.2: Províncias geológicas, os círculos em vermelho representam os sismos, cujas magnitudes variam de 3,5 a 6,2. As barras em azul, verde e laranja são estimativas das direções de tensão horizontal máxima (SHmax) dos mecanismos de falha inversa, transcorrente e normal, respectivamente (o tamanho de cada barra denota a qualidade dos dados). As barras em azul que estão abertas representam dados hidráulicos. As áreas em rosa são os crátons arqueanos e paleoproterozóicos, os em cinza são neoproterozóicos, paleozóicos e os em amarelo são as principais bacias fanerozóicas (Pt = bacia do Pantanal). TBL é a sigla do Lineamento Transbrasiliano. Na Província do Tocantins, AFB = cinturão do Araguaia, MA = Arco Magmático NeoProterozóico e GM = Maciço Arqueano de Goiás. Imagem retirada de Assumpção e Sacek, 2013).

na profundidade do limite entre litosfera e astenosfera poderia acarretar em aumento do fluxo de calor e dessa forma, alterar a reologia da litosfera (Assumpção et al., 2004).

No trabalho de tomografia de Feng et al. (2007), onde foram utilizadas velocidades de grupo da onda Rayleigh (somente modos normais), foi observada uma forte redução na velocidade de propagação da onda S sob os Andes. A presença de reduções de velocidade significativamente mais tênue sob as bacias do Chaco, oeste do Paraná e Pantanal (Figura 1.4) aparentemente indicam afinamento litosférico. A subida da astenosfera nesta região poderia, portanto, mudar a estrutura reológica da litosfera deixando-a mais frágil.

O trabalho de espessura elástica efetiva da litosfera (Te) na América do Sul realizado 


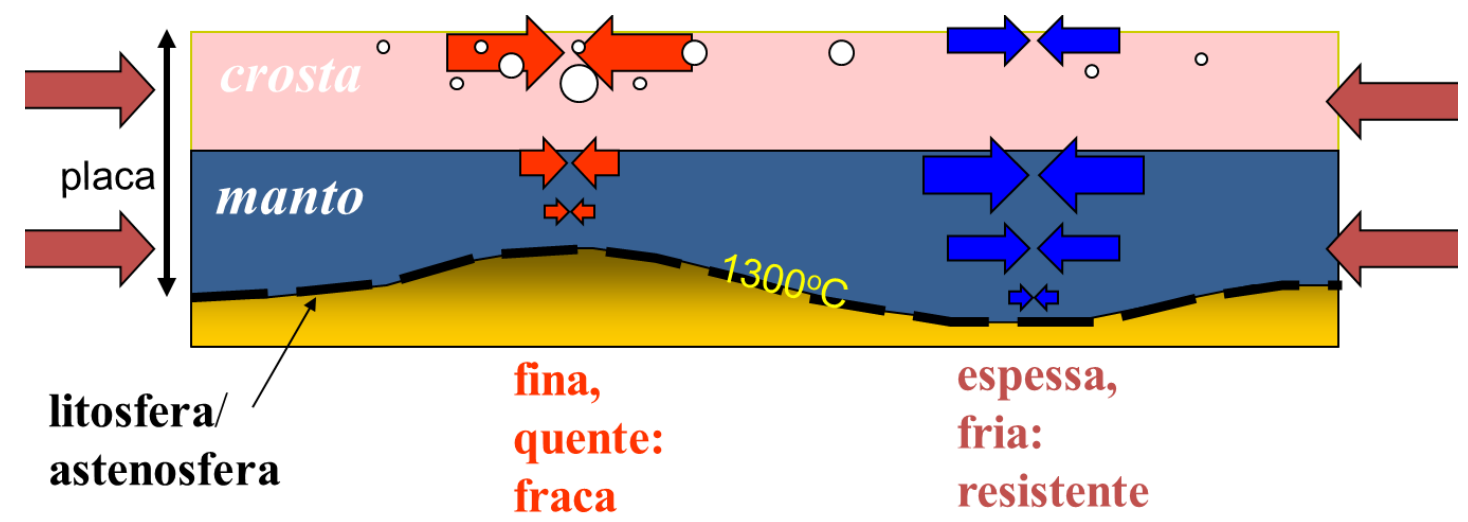

Figura 1.3: Um modelo possível para o que ocorre em regiões de maior sismicidade, o qual apresenta zonas de baixa velocidade para as ondas sísmicas, podendo estar associado ao afinamento litosférico e como consequência soerguimento da astenosfera. Imagem retirada de (Assumpção et al. 2004).

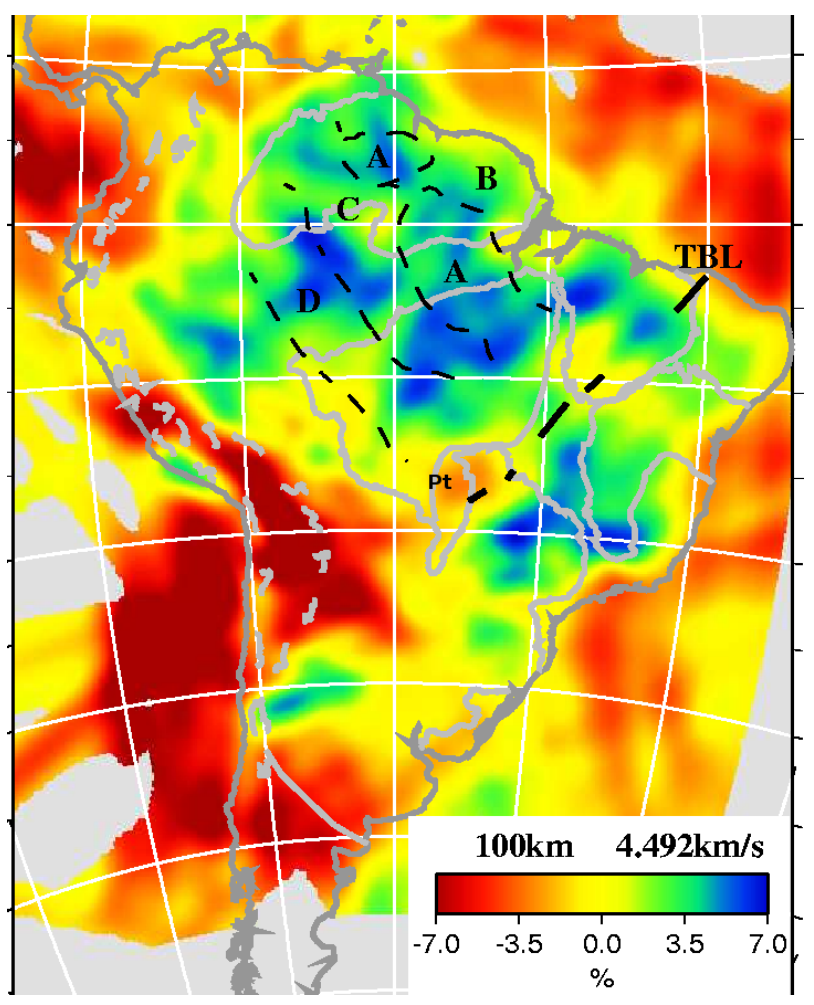

Figura 1.4: Anomalias da onda S em $100 \mathrm{~km}$ de profundidade, obtidas com dispersão das ondas de superfície, imagem retirada de (Feng et al., 2007). A região de anomalia negativa da bacia se situa entre $15^{\circ}$ a $20^{\circ} \mathrm{S}$ e a $55^{\circ}$ a $60^{\circ} \mathrm{W} . \mathrm{Pt}=$ Pantanal. TBL: Lineamento Transbrasiliano.

por Pérez-Gussinyé et al. (2007) mostra um baixo Te para a litosfera da Bacia do Pantanal que é coincidente com as anomalias de baixa velocidade e, dessa forma, poderia corroborar para uma interpretação de uma litosfera mais fina (Figura 1.5). 


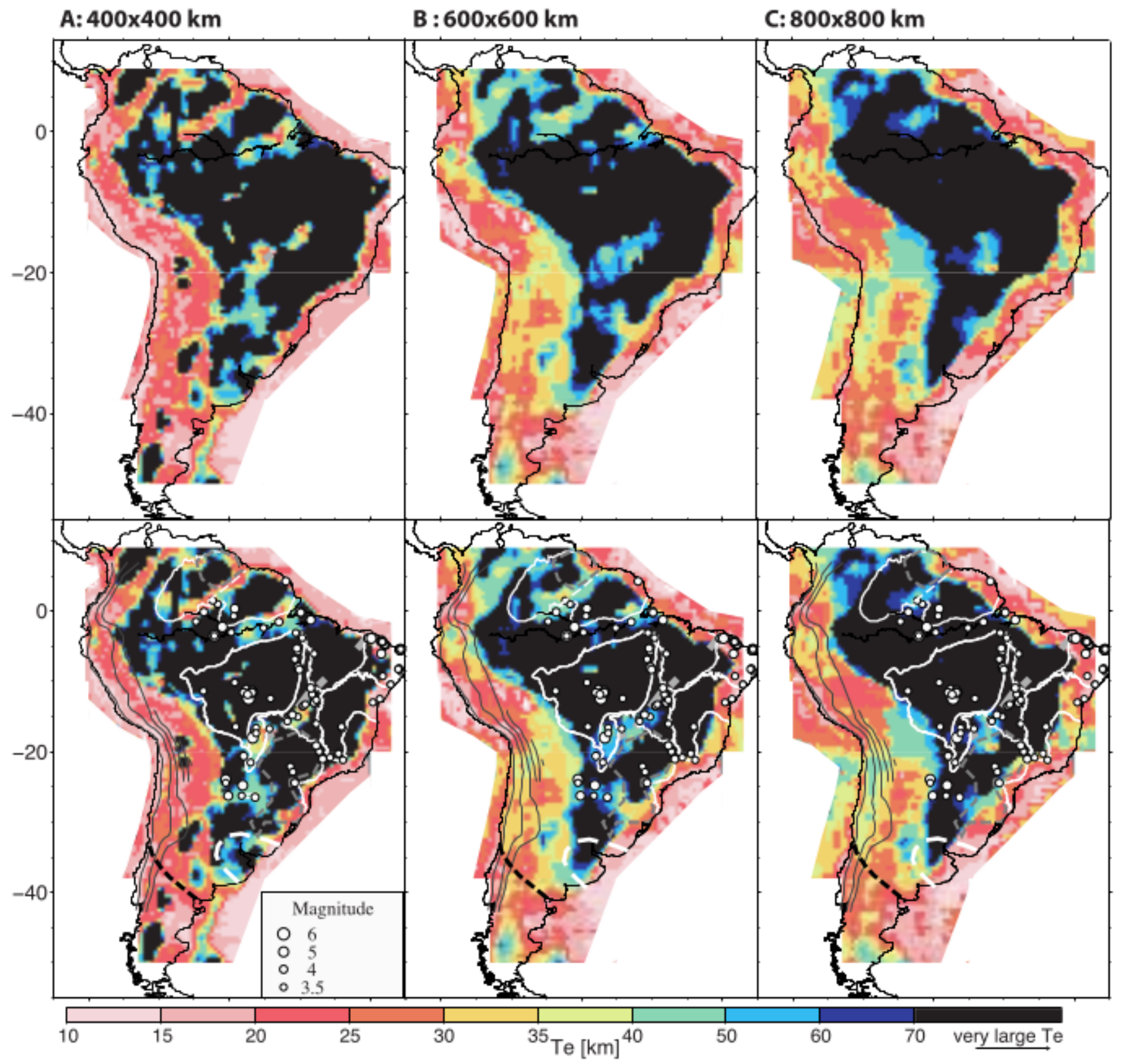

Figura 1.5: Valores de Te (espessura elástica efetiva da litosfera) para a América do Sul. Imagem retirada Pérez-Gussinyé et al. (2007). 
Capítulo 2

\section{Teoria e Métodos Empregados}

\subsection{Ondas de Superfície, Dispersão e Modos Normais}

Ondas de superfície são o resultado do acoplamento das ondas P e S. Sua energia é concentrada nas camadas mais próximas da superfície da Terra. Por meio de um espalhamento geométrico, a energia decai aproximadamente com o inverso da distância da fonte. Como as ondas Rayleigh e Love são sensíveis às variações de velocidade no manto superior, ao medirmos a velocidade com a qual essas ondas se propagam, podemos obter informações sobre as variações de propriedades físicas da litosfera. As velocidades são determinadas a partir da análise dos registros feitos por estações para diferentes fontes sísmicas (Radi et al., 2017).

Através da interferência construtiva na superfície entre as ondas P e SV são geradas as ondas Rayleigh, podendo esta existir em qualquer superfície livre. As oscilações da mesma são contidas no plano vertical sem componente tangencial (Figura 2.1a). Os movimentos de partícula na componente radial e vertical possuem uma defasagem de $90^{\circ}$ causando movimentos de partícula elípticos retrógrados. Sendo sua amplitude visível nas componentes radial e vertical.

A onda Love resulta da interferência construtiva da onda S polarizada horizontalmente (Figura 2.1b). A sua existência relaciona-se com o aumento da velocidade com a profundidade, sendo visível na componente transversal. A onda Love apresenta velocidade maior que a onda Rayleigh, pois é observada antes no sismograma. 


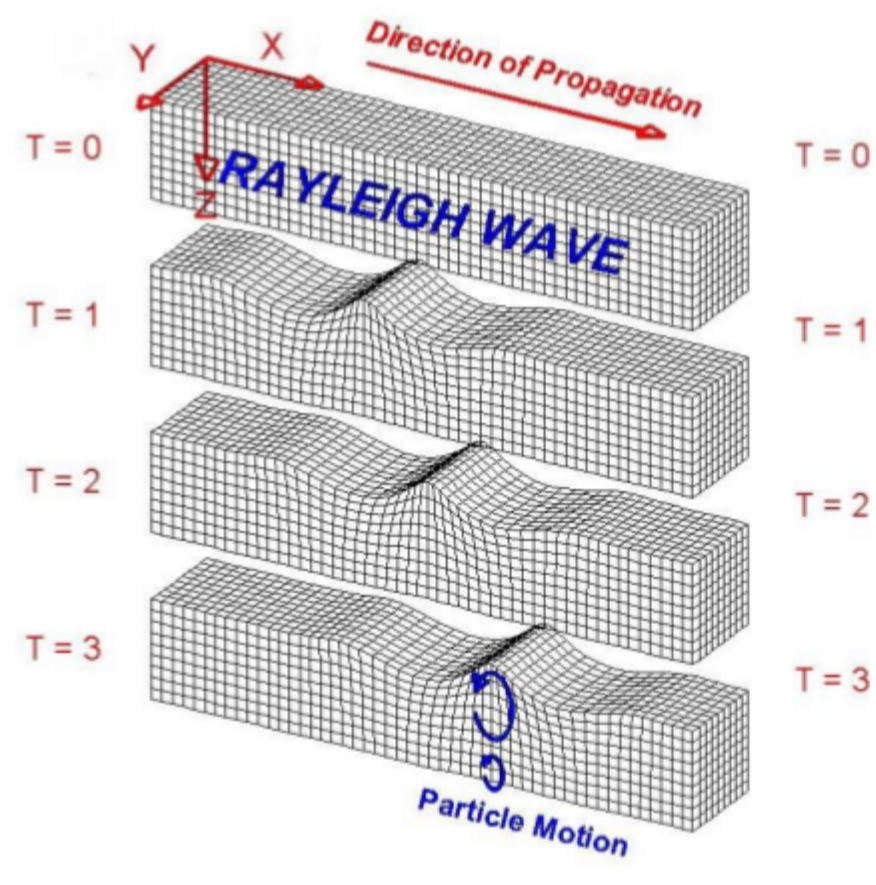

(A)

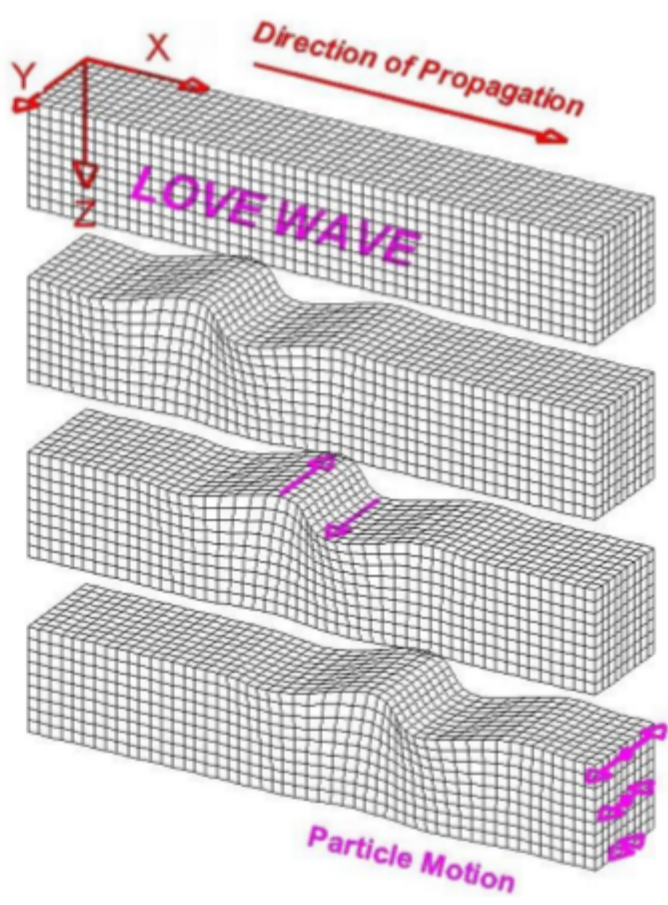

(B)

Figura 2.1: Propagação e movimento de partícula das Ondas Rayleigh e Love. Imagem adaptada de Feng (2004).

Os métodos que usam as ondas de superfície para o estudo das camadas da Terra dependem do fenômeno da dispersão, no qual períodos maiores possuem maiores velocidades. Os períodos curtos amostram estruturas mais próximas à superfície, enquanto os longos comprimentos de ondas são mais sensíveis às variações de velocidade que ocorrem em camadas mais profundas da Terra.

A velocidade de grupo $U(\omega)$ e a de fase $C(\omega)$ estão relacionas pela equação 2.1 , sendo $k$ o número de onda. Como $U(\omega)$ é a derivada de $C(\omega)$, uma mínima alteração na velocidade de fase, pode acarretar em grandes variações na velocidade de grupo. Comumente, na Terra $C(\omega)$ diminui com a frequência, no qual se tem $\left(\frac{\partial C}{\partial k}\right.$ menor que 0$)$ implicando em $C(\omega)$ ser maior que $U(\omega)$.

$$
U=\frac{\partial(k C)}{\partial k}=C+\frac{\partial C}{\partial k}
$$

Modos normais são de frequência muito baixa, portanto, difíceis de observar em um sismograma. Esses modos são gerados na Terra a partir de ondas sísmicas de grande com- 
primento de onda que interferem para formar ondas estacionárias. Apenas os terremotos com grandes liberações de energia são capazes de gerar oscilações livres que são aparentes na maioria dos sismogramas.

Esses modos descrevem a oscilação livre de uma esfera e podem ser divididos conforme a onda de superfície trabalhada. Os esferoidais ocorrem com as ondas P e SV (Rayleigh). Os modos toroidais envolvem apenas ondas SH (Love) e não existem no núcleo externo, visto que, a onda S não se propaga em fluídos.

Para entende-los, é instrutivo considerar o modelo 1D, sendo este de uma corda vibrante fixa em ambas as extremidades (Figura 2.2a). O caso 3D (Figura 2.2b), é semelhante ao $1 \mathrm{D}$, pois exige que as ondas estacionárias se interfiram e se encontrem em um ponto nulo, obedecendo a equação (2.2).
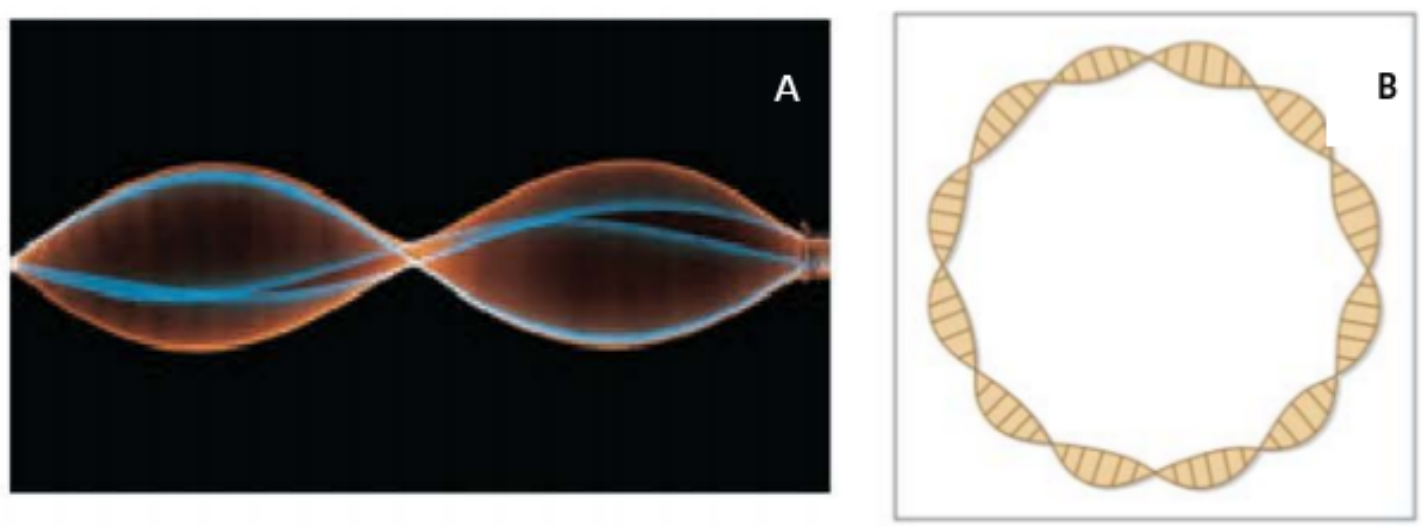

Figura 2.2: Modelos 1D e 3D de Oscilação livre. Imagens adaptadas de Freedman et al. (2009) e OpenCourseWare 2008)

$$
\frac{\partial^{2} y}{\partial x^{2}}=\frac{1}{C^{2}} \frac{\partial^{2} y}{\partial t^{2}}
$$

A solução da equação 2.2 é $\sin \left(\frac{\omega L}{c}\right)$. Igualando a solução a zero, temos que $\frac{\omega L}{c}=(n+1) \pi$. Sendo $\mathrm{n}=0,1,2$ e assim por diante. Logo há infinitas frequências discretas $\left(\omega_{n}\right)$ que satisfazem a equação 2.2, sendo conhecidas de autofrequências. Para $n=0$ temos o modo fundamental (facilmente observado) e todos $\mathrm{n} \geq 1$ correspondem aos modos superiores. 


\subsection{Núcleo de Sensibilidade}

Com mencionado antes, períodos maiores possuem velocidades maiores. Logo, ondas com períodos diferentes possuem sensibilidade às interfaces em profundidades diferentes. Para relacionar as velocidades de $\mathrm{C}$ e U de períodos distintos com as estruturas em diferentes profundidades, é importante saber $\left(\frac{\partial C}{\partial \beta}\right)$ e $\left(\frac{\partial U}{\partial \beta}\right)$ a derivada parcial de cada velocidade em função da velocidade da onda S.

As derivadas parciais implicam que uma derivada zero significa que qualquer perturbação de velocidade de onda S não influência a velocidade de U ou C, contudo uma sensibilidade elevada significa que uma pequena perturbação na velocidade de onda S causará grande variação nas velocidades. Neste sentido, podemos observar na Figura 2.3 que as ondas Rayleigh e Love de períodos longos são sempre mais sensíveis as profundidades maiores, enquanto que as ondas de períodos curtos são mais sensíveis à parte rasa.
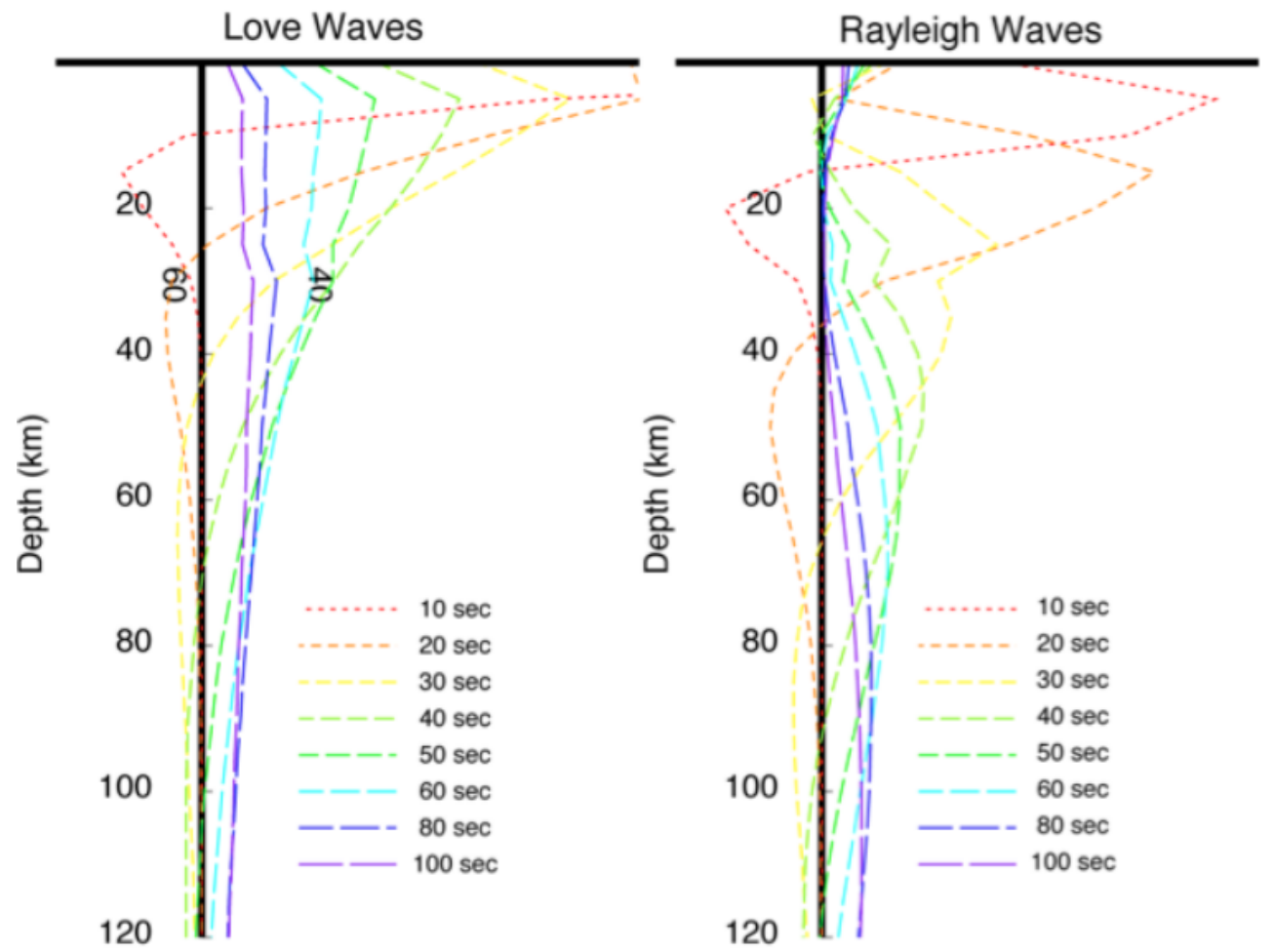

Figura 2.3: Núcleos de sensibilidade das ondas Love à esquerda e à direita Rayleigh, seus períodos variam de 10 a 100s para um perfil de velocidade da crosta continental. Retirado de Pasyanos 2005). 


\subsection{Processamento}

O processamento dos dados é dividido em seis etapas (Figura 2.4).

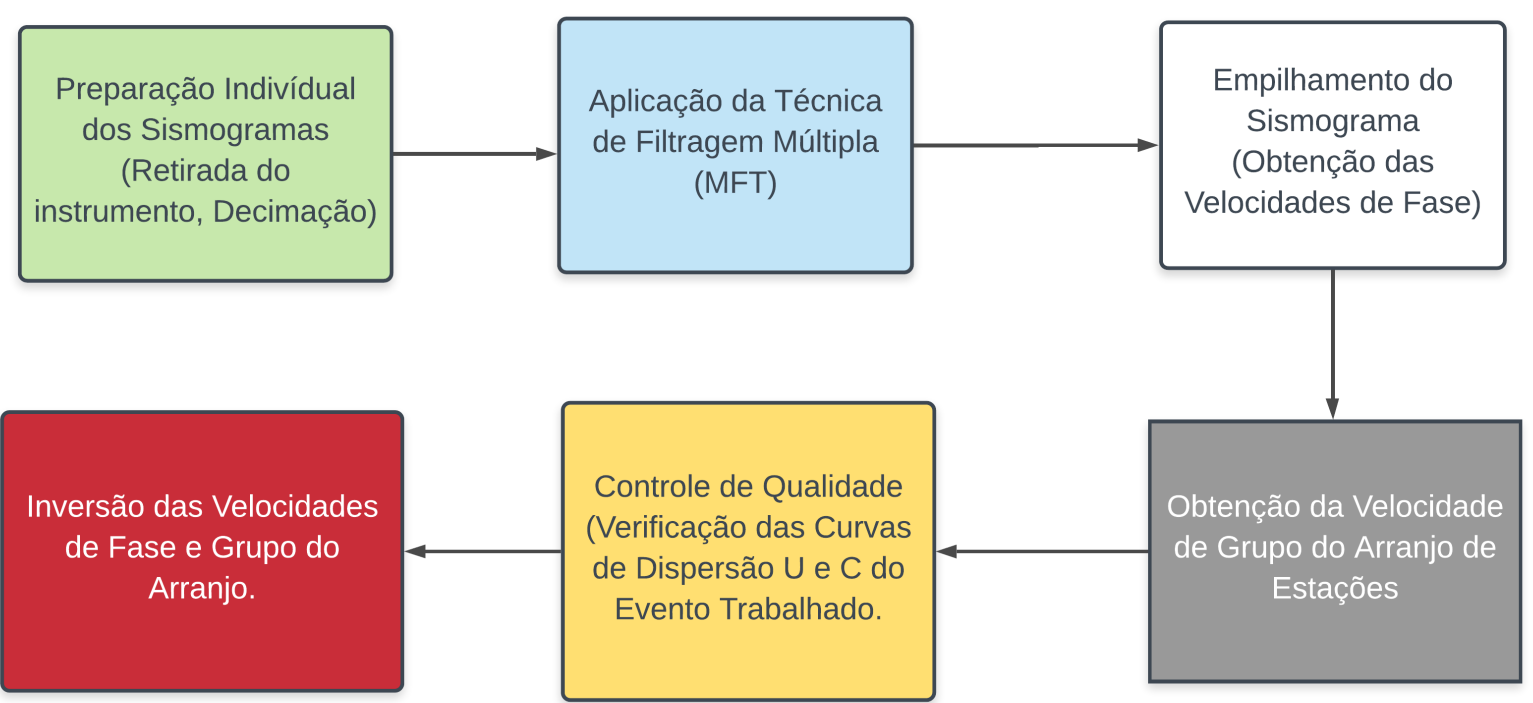

Figura 2.4: Fluxograma de processamento, dividido em seis etapas, sendo elas preparação individual, Técnica de Filtragem Múltipla, empilhamento, obetenção das velocidades de grupo do arranjo, controle de qualidade e inversão das velocidades encontradas.

\subsubsection{Preparação individual}

Por meio do SAC (Seismic Analysis Code) (Goldstein et al., 2003) iniciamos a leitura individual de cada sismograma (Figura 2.5). Foi retirada a tendência linear e utilizando arquivos de polos e zeros (arquivo de resposta para cada estação), por meio do comando transfer retiramos a resposta do instrumento, para que assim as amplitudes do sismograma representem a medida do deslocamento do solo.

O sismograma original possui em torno de 200 mil amostras, para a aplicar a Técnica de Filtragem Múltipla é necessário decima-lo (reamostragem), pois a mesma não suporta esse valor. Posteriormente é feita uma mudança de sistemas de coordenadas das componentes do sismograma, de vertical/norte/sul para vertical/radial/transversal, uma vez que as ondas Love e Rayleigh são observadas com maiores amplitudes nas componentes transversais e radiais/verticais, respectivamente (Figura 2.6). 


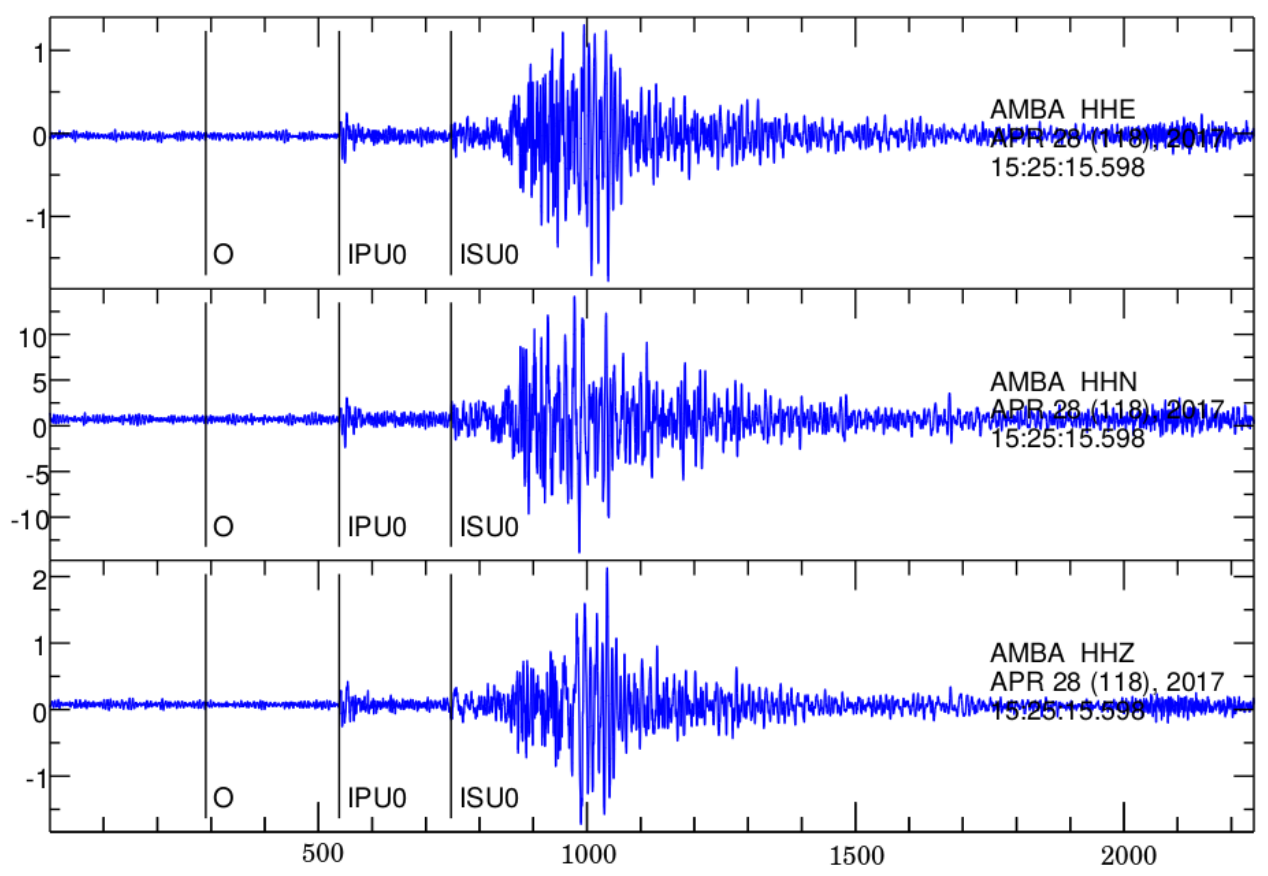

Figura 2.5: Sismograma original, evento com epicentro no Chile de magnitude $m_{b} 5,9$. O símbolo O corresponde ao tempo de origem, IPU0 corresponde a primeira chegada da onda $\mathrm{P}$ e ISU0 corresponde a primeira chegada da onda S. O eixo $\mathrm{x}$ representa o tempo em segundos e o eixo y esta em contagem.

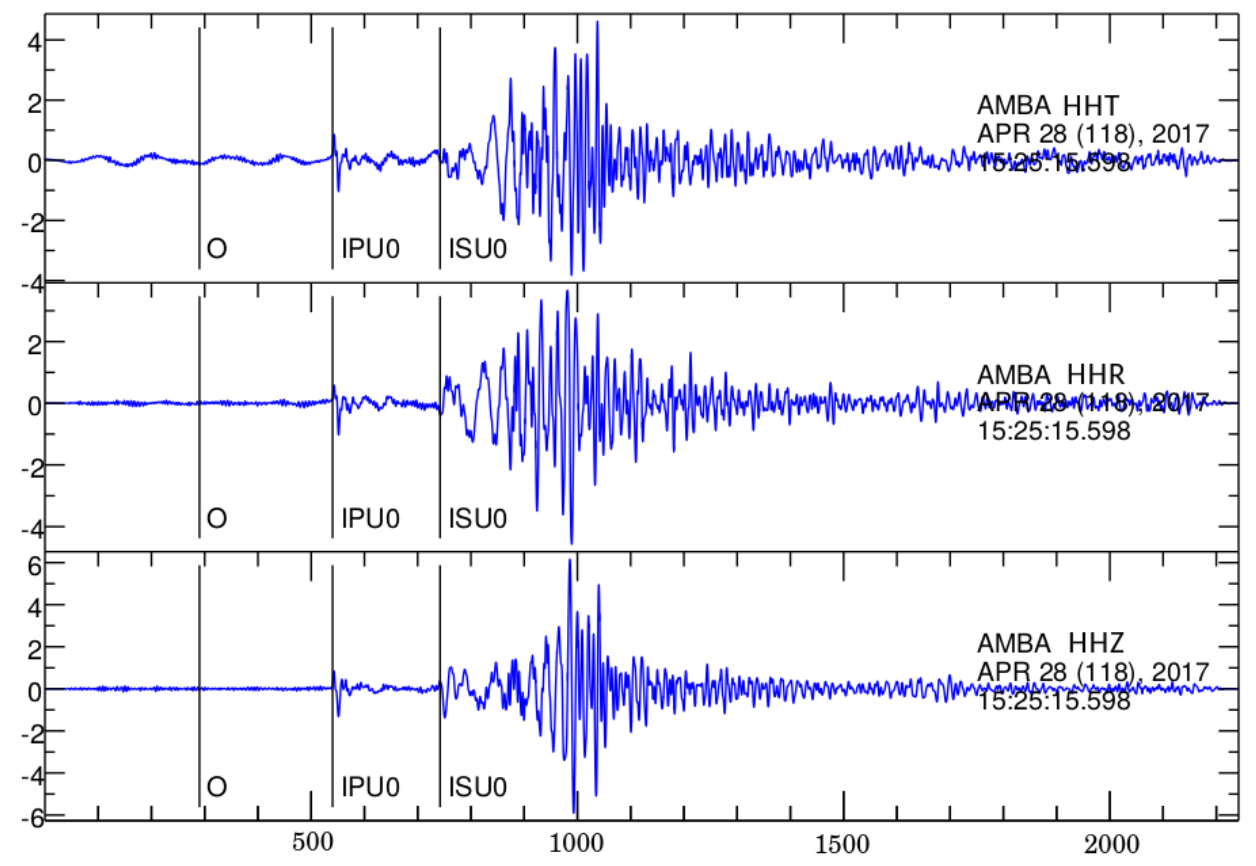

Figura 2.6: Sismograma em deslocamento, decimado e rotacionado, evento com epicentro no Chile de magnitude $m_{b} 5,9$. O símbolo $\mathrm{O}$ corresponde tempo de origem, IPU0 corresponde a primeira chegada da onda P e ISU0 corresponde a primeira chegada da onda S. O eixo x representa o tempo em segundos e o eixo y representa o deslocamento do chão em $\mu \mathrm{m}$. 


\subsubsection{MFT (Multiple Filtering Techniques) e Aplicação}

Denominada de Técnica de Filtragem múltipla (Dziewonski et al., 1969) e (Herrin e Goforth, 1977), este método é utilizado para se obter a velocidade de grupo das ondas Rayleigh e Love. Essa técnica consiste da aplicação de filtros passa-banda estreitos, onde é isolado o pacote das ondas que correspondem à frequência central de cada filtro. Em seguida, a velocidade de grupo para aquela frequência pode ser determinada ao dividirmos a distância epicentral pelo tempo de percurso do pacote de ondas. Para isso, é necessário que haja no cabeçalho do sismograma o tempo de origem e a distância epicentral. Neste trabalho, utilizamos o filtro Gaussiano, como apresentado por Herrmann e Ammon (2002) que é dado pela equação 2.3:

$$
H(\omega)=e^{\frac{-\alpha\left(\omega-\omega_{0}\right)^{2}}{\left(\omega_{0}^{2}\right)}}
$$

Sendo $\alpha$ uma constante que controla a largura do filtro e $\omega_{0}$ a frequência central. Este filtro permite que obtenhamos uma boa resolução de cada frequência central, assim como da velocidade.

A rotina de Herrmann e Ammon (2002) carrega os sismogramas que já foram processados no SAC, no qual os arquivos possuem em seus cabeçalhos informações como: latitude, longitude e distância epicentral do evento. Posteriormente escolhemos o valor de $\alpha$ que se relaciona com a Faixa Epicentral (intervalos de distâncias epicentrais, por exemplo, para um evento com distância epicentral de $1500 \mathrm{~km}$, usa-se a faixa epicentral de $1000 \mathrm{~km}$, que se relaciona com $\alpha=25$ ) e pode ser ajustado conforme a Tabela 2.1 Herrmann e Ammon (2002). Em seguida, a MFT é iniciada.

Considerando o sismograma original (Figura 2.7), usamos um $\alpha=50$, visto que o evento apresenta distância epicentral de aproximadamente $2000 \mathrm{~km}$. A filtragem da componente vertical para a onda Rayleigh gera a velocidade de grupo do modo fundamental (Figura 2.8).

Tabela 2.1 - Relação entre Faixa Epicentral e $\alpha$

\begin{tabular}{lc}
\hline \hline Faixa Epicentral $(\mathrm{km})$ & $\alpha$ \\
\hline 1000 & 25 \\
2000 & 50 \\
Continua na próxima página...
\end{tabular}


Tabela 2.1 - Continuação

\begin{tabular}{ll}
\hline \hline Faixa Epicentral $(\mathrm{km})$ & $\alpha$ \\
\hline \multirow{2}{*}{4000} & 100 \\
8000 & 200 \\
& \\
\hline
\end{tabular}

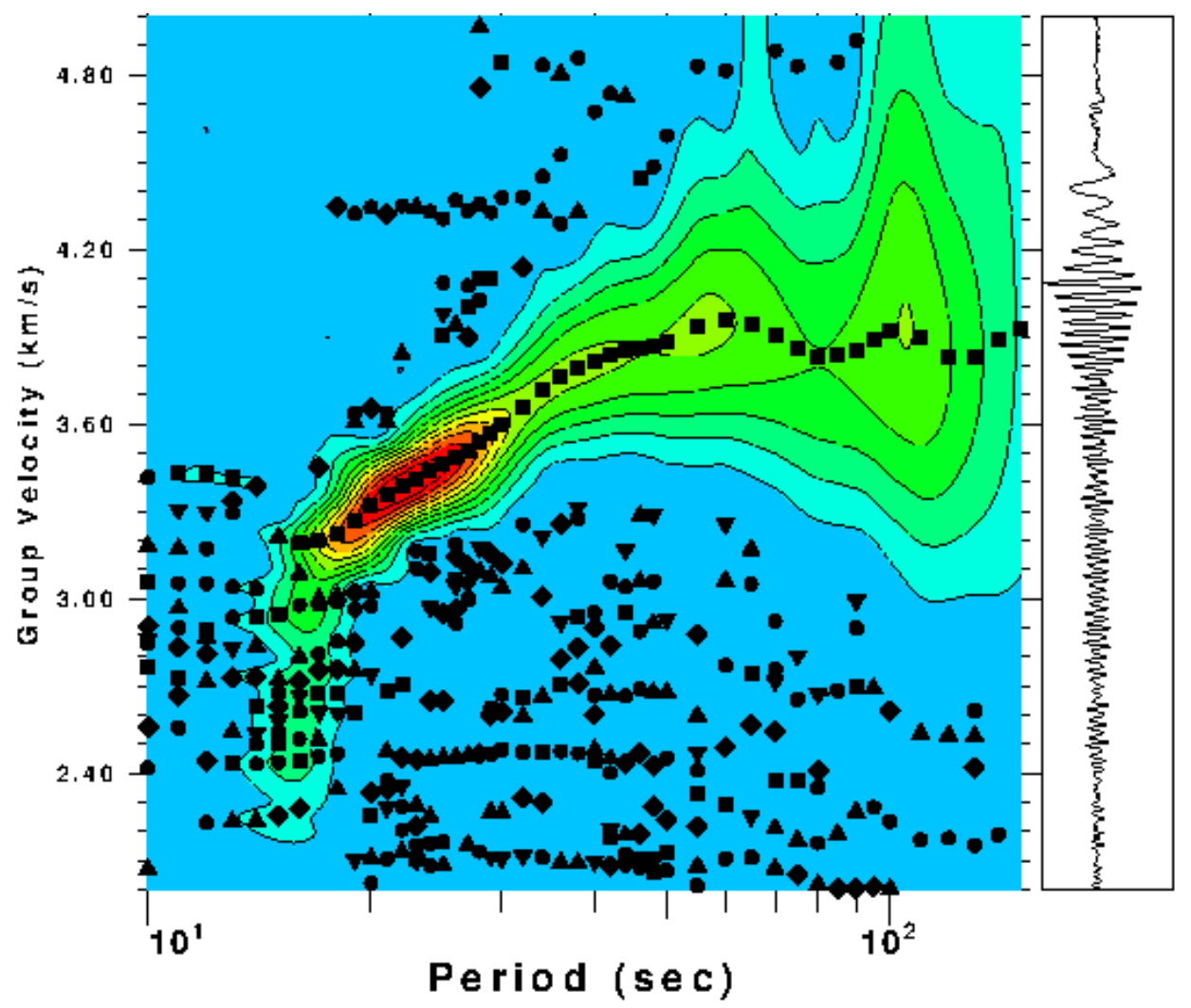

Figura 2.7: Curvas de dispersão de velocidade de grupo da onda Rayleigh de um evento. O eixo x representa o período, e o y a velocidade. Nesta envoltória é possível observar o sismograma completo, contendo modo fundamental de vibração, sua envoltória inicia com período de 11 a 120 segundos e velocidade de 3.5 a $3.8 \mathrm{~km} / \mathrm{s}$. Os quadrados em preto representam os pontos mais confiáveis na curva de dispersão, os círculos e triângulos são ruídos. A cor vermelha representa a região com maior energia na envoltória. 


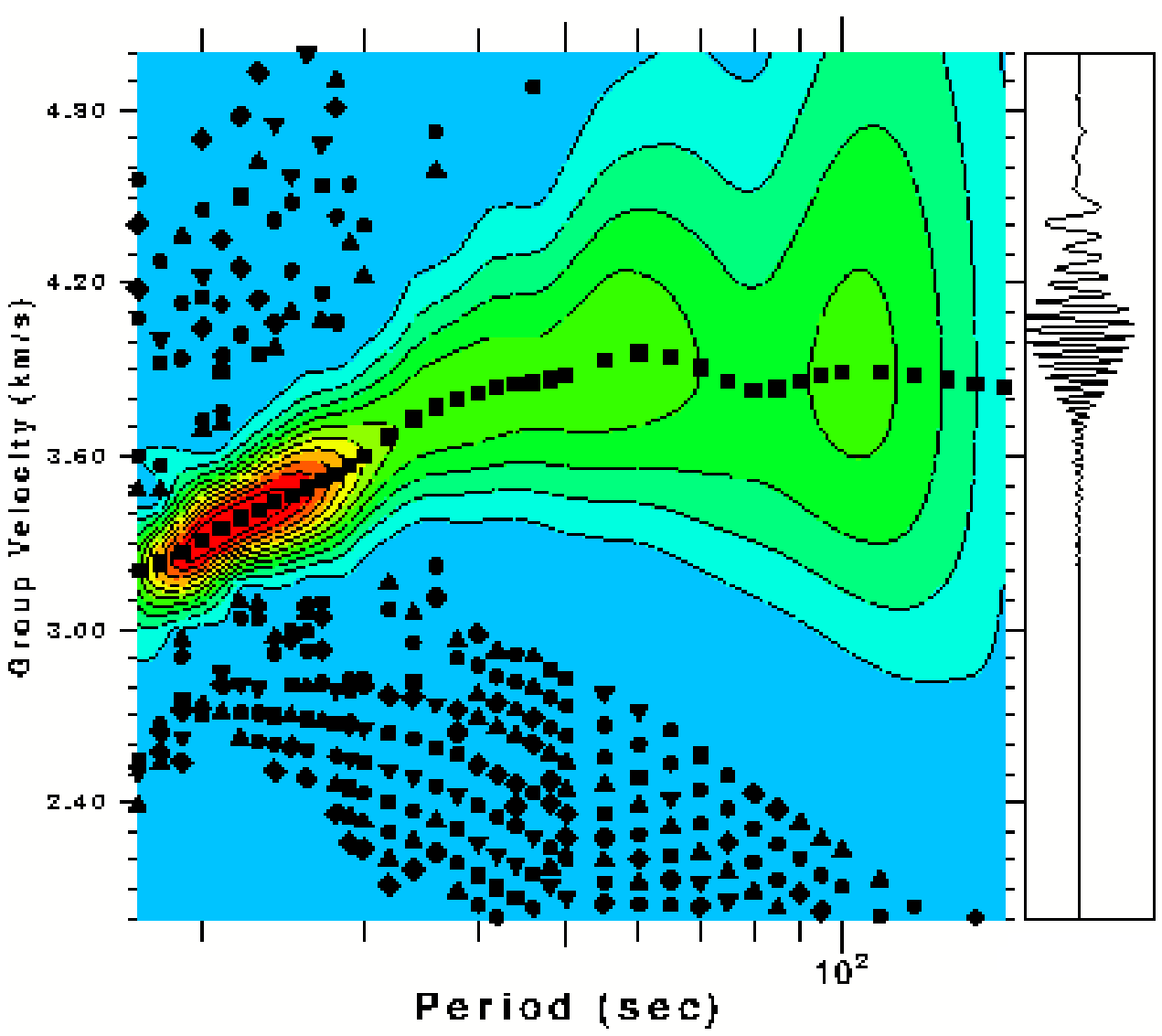

Figura 2.8: Curvas de dispersão, envoltória já filtrada, $\alpha=50$, para o modo fundamental da onda Rayleigh do o evento da figura 2.7. O eixo x representa o período, e o y a velocidade. Nesta envoltória o modo fundamental com período de 11 a 120 segundos e velocidade de 3.5 a $3.8 \mathrm{~km} / \mathrm{s}$. Os quadrados em preto representam os pontos mais confiáveis na curva de dispersão, os círculos e triângulos são ruídos. Pode-se perceber que área grande quantidades de pontos com ruído em torno de $3,00 \mathrm{~km} / \mathrm{s}$ foi descartada após a passagem da MFT.

\subsubsection{Velocidade de Grupo do Arranjo de Estações}

As curvas de dispersão de U obtidas após a aplicação da MFT são entre a estação e o evento. Partindo do pressuposto que a geologia entre as estações seja semelhante, buscamos obter a $U_{\text {media }}$ entre as estações (Figura 2.9). A estações em magenta pertencem a rede XC, são temporárias e foram instaladas pelo Projeto Três Bacias (Pantanal-Chaco-Paraná Basin (PCPB): Crust and Upper Mantle Seismic Structure and Evolution). As estações em azul são da rede BL e a em preto, rede BR. As redes BR e BL estão incluídas na Rede Sismográfica Brasileira (RSBR).

Para isso as velocidades que foram encontradas são interpoladas para períodos inteiros, em seguida foi obtido o tempo de percurso de cada período, dividindo a distância epicentral 


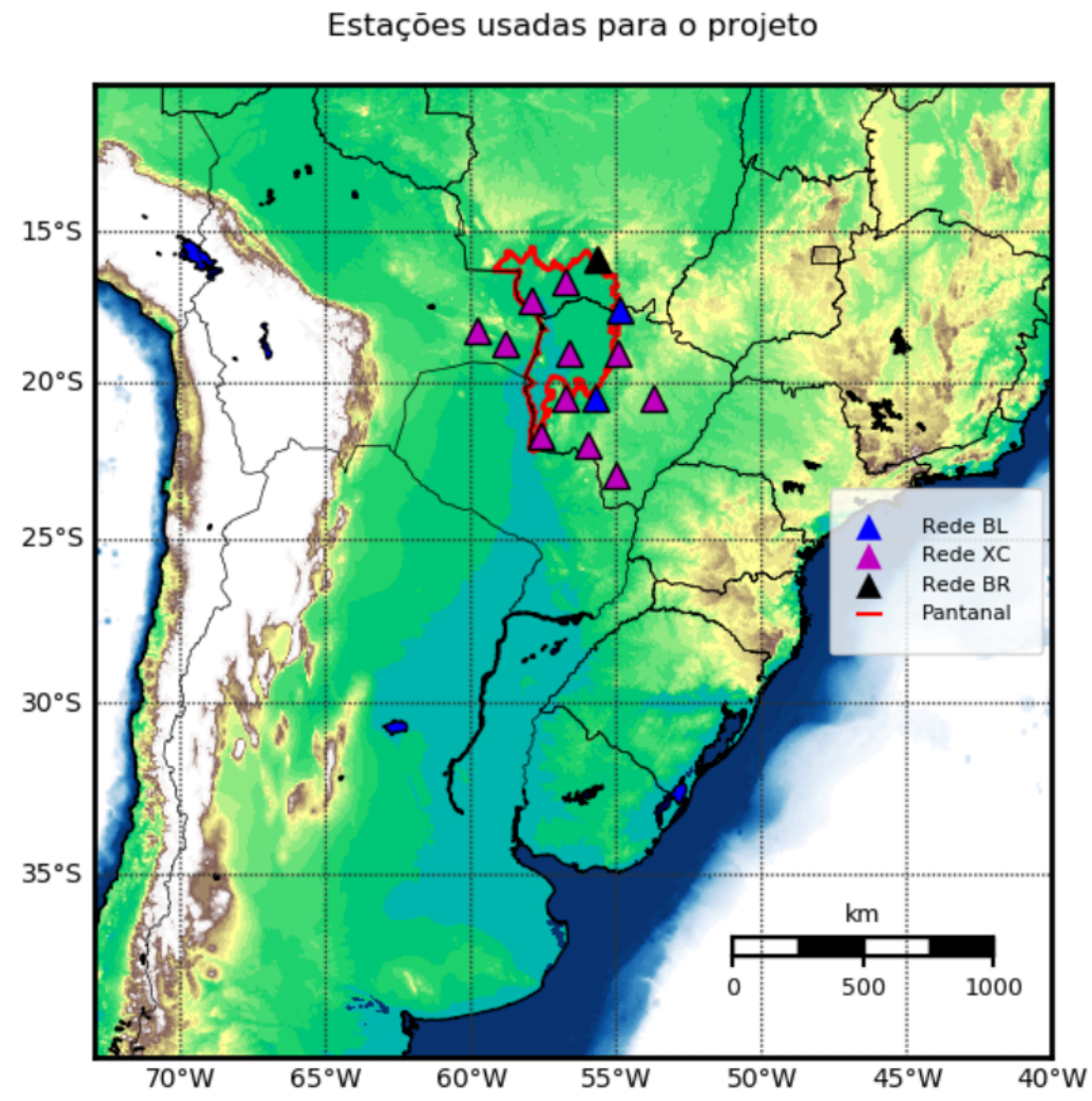

Figura 2.9: Estações Sismográficas instaladas na área de estudo, inseridas em um mapa de topografia. As estações em azul são pertencentes à rede $\mathrm{BL}$, as em roxo pertencem à rede temporária XC e única em preto, pertence à $\mathrm{BR}$.

pela velocidade interpolada de cada período.

Após, realizarmos esse passo em cada estação, gera-se o gráfico de tempo de percurso pela distância epicentral, visto que as incertezas estão contidas no tempo de percurso, onde é feito o ajuste de reta para cada período observado em suas respectivas estações. (Figura 2.10). A $U_{\text {media }}$ de cada período é obtida quando se calcula o inverso do coeficiente angular.

\subsubsection{Empilhamento dos Sismogramas Filtrados}

Após a MFT, obtemos as velocidades de grupo do evento para cada estação, assim como seus respectivos sismogramas filtrados. Em seguida realizamos o empilhamento de todos os sismogramas filtrados para o respectivo evento, com o processo do_pom Herrmann e Ammon, 2002) para obter as velocidades de fase para cada harmônico desejado (Figura 2.11). 


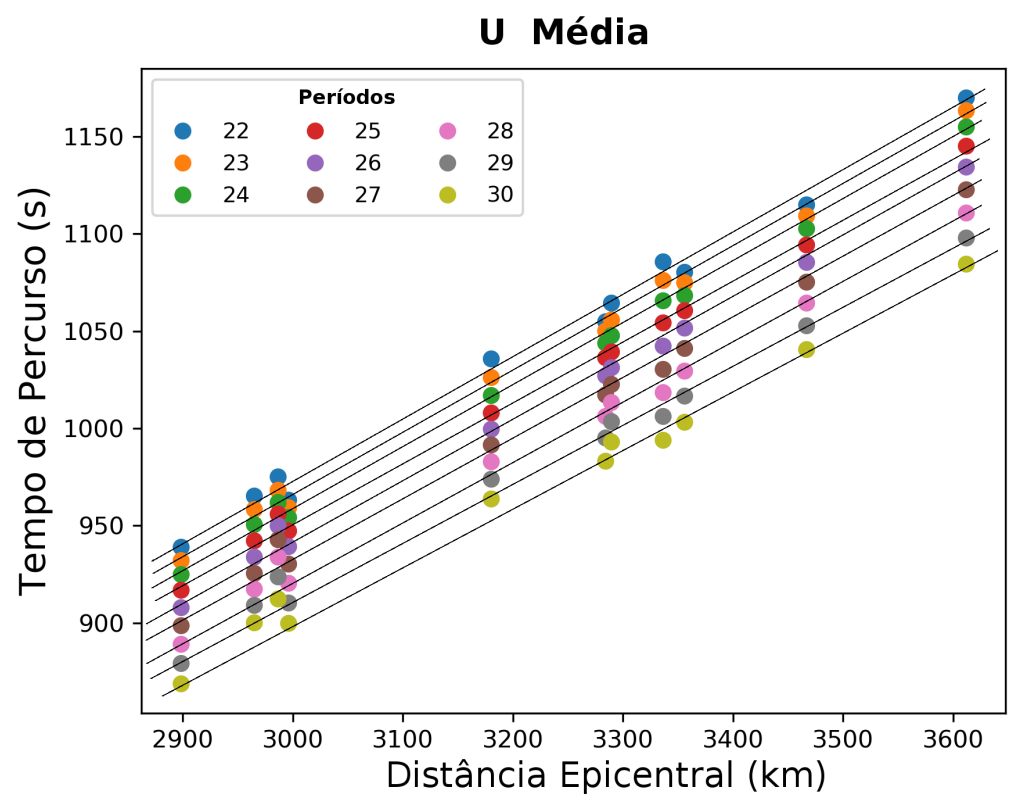

Figura 2.10: Gráfico para a obtenção da velocidade de grupo média em cada período, no arranjo de estações da área de estudo. Onde velocidade média é o ajuste de reta entre os pontos de cada período.

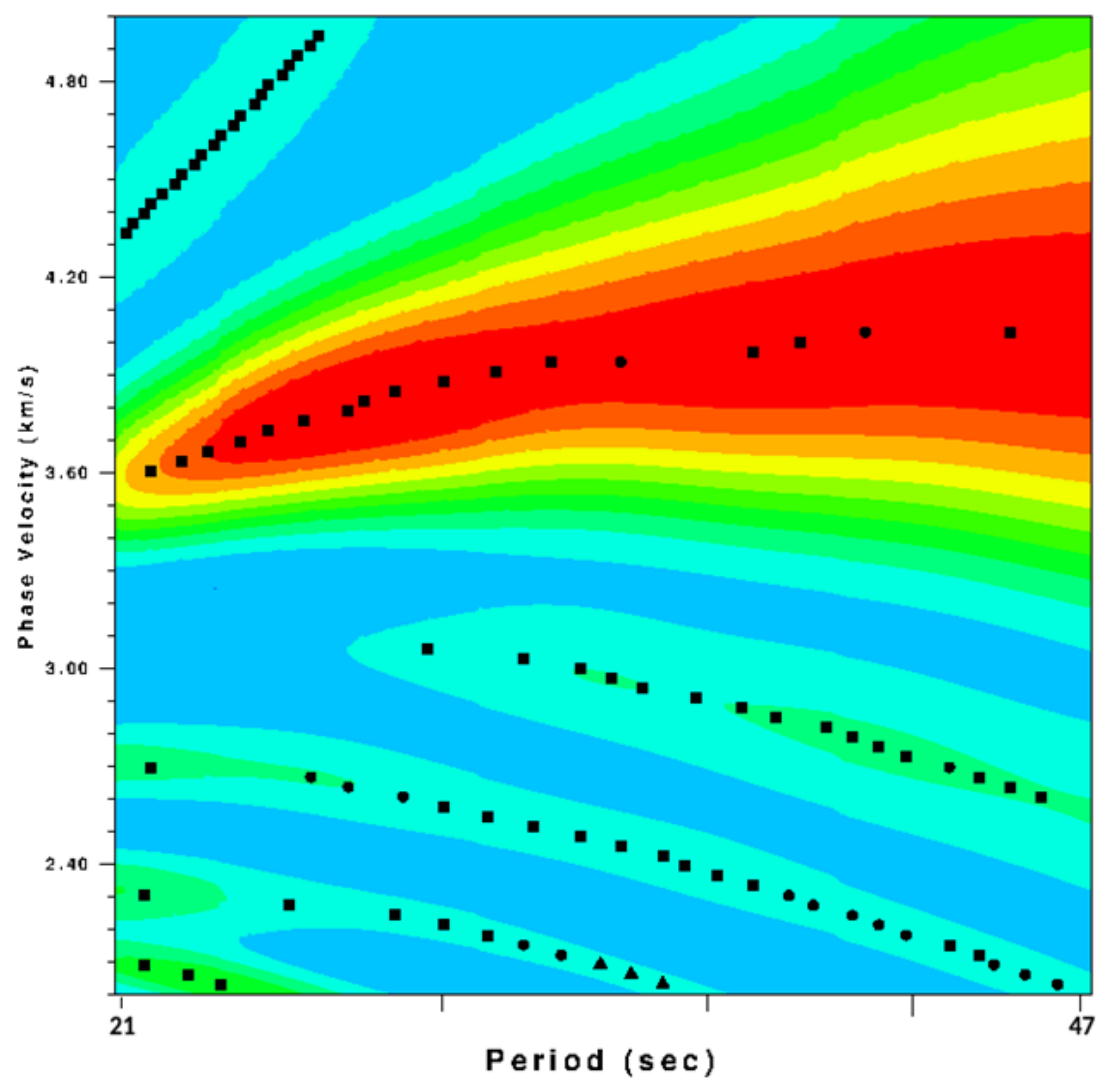

Figura 2.11: Empilhamento dos sismogramas filtrados. Calculo das velocidades de fase entre as estações que foram utilizadas. No eixo x (período), o primeiro marcador representa 21 e o último 47 segundos. No eixo y está representado a velocidade de fase em torno de 3.60 a 3,8 $\mathrm{km} / \mathrm{s}$. Os ponto em preto representam os pontos de dispersão. A cor vermelha representa a região com maior energia na envoltória. 


\subsubsection{Controle de Qualidade}

Devido à complexidade geológica da Bacia, alguns dados não forneceram os resultados esperados. Por exemplo, na Figura (2.12) se observa que as envoltórias estão decaindo, contrapondo o fato que períodos maiores apresentam maiores velocidades. Há um padrão, entre 6 a 7,5 segundos, onde há a variação crescente dos períodos com a velocidade, no entanto, foi necessário reprocessá-lo.

A velocidade de fase é obtida pelo empilhamento dos sismogramas, logo a razão por não conseguirmos obte-la está relacionada com os sismogramas filtrados erroneamente ou o dado analisado não é de boa qualidade.

Como esses sismogramas são obtidos com a aplicação da MFT, suas velocidades de grupo também estarão com má qualidade, dessa forma, observamos que comparar as curvas de U de cada estação lado a lado, seria um bom controle de qualidade, sendo a Figura (2.13) um exemplo de um bom dado, visto que, é observado o $1^{\circ}$ modo superior de vibração da Rayleigh, e as velocidades de grupo de cada estação apresentam o mesmo padrão. As curvas de dispersão de U das estações que apresentam padrão diferente das demais, são verificadas e analisadas novamente, no entanto, se o padrão errôneo ainda persiste, a curva de dispersão e o sismogramas são descartados.
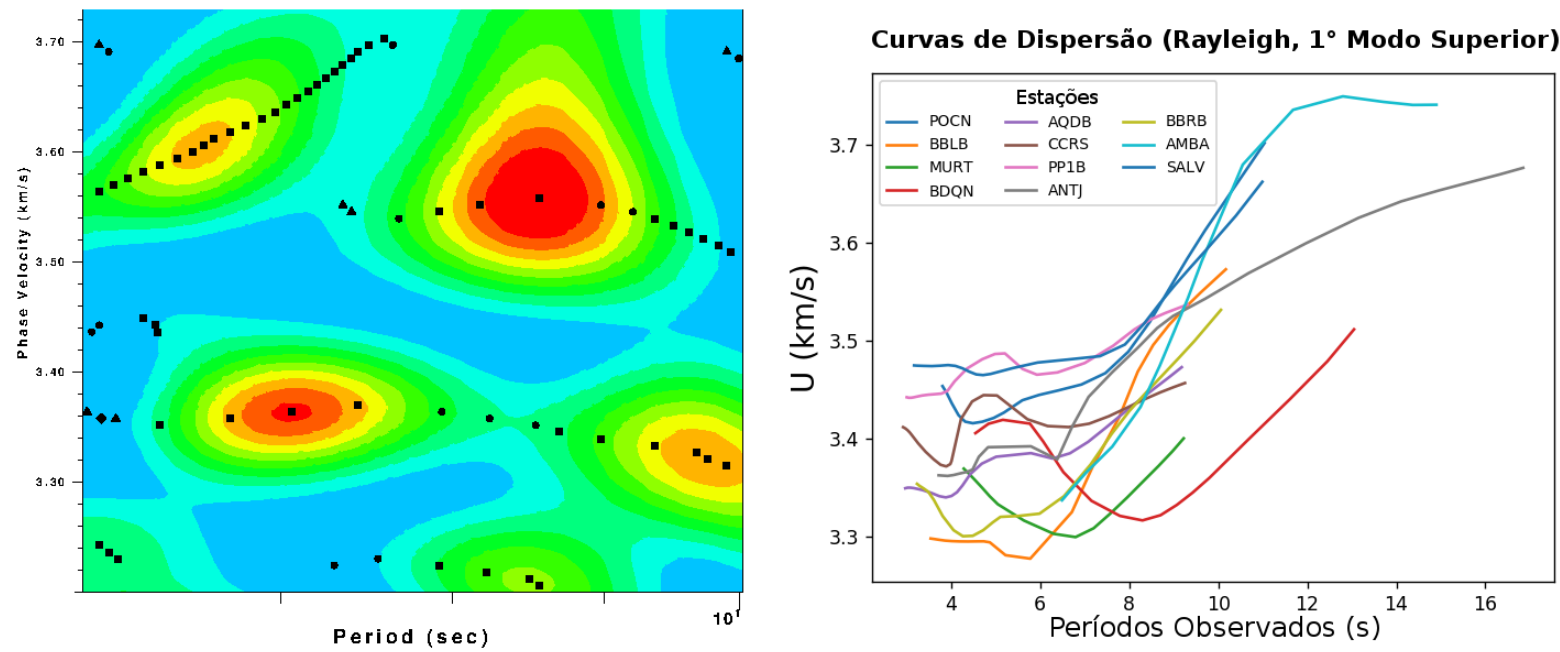

Figura 2.12: Curva de dispersão de baixa qualidade. À esquerda temos a velocidade de fase para o primeiro modo superior da onda Rayleigh. À direita temos as curvas de U em cada estação observadas em cada estação. 

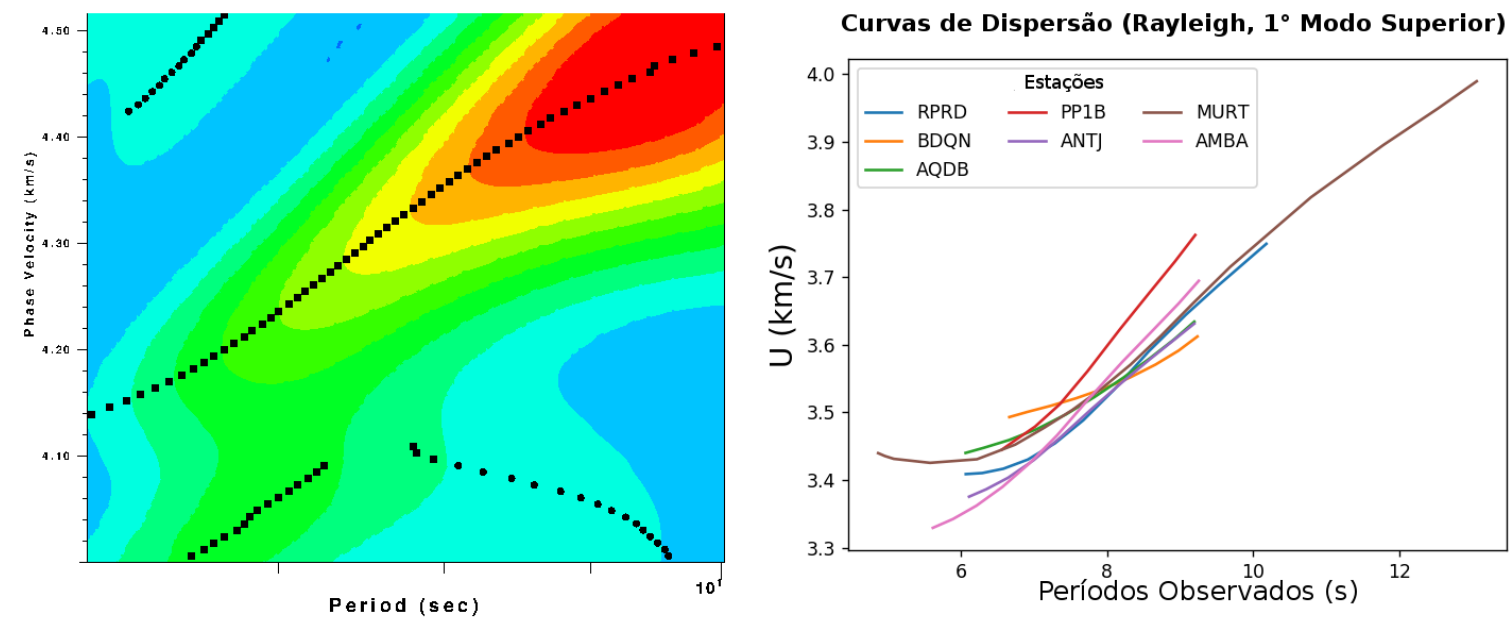

Figura 2.13: Curvas de dispersão com boa qualidade. À esquerda temos a velocidade de fase para o primeiro modo superior da onda Rayleigh. À direita temos as curvas de U em cada estação observadas em cada estação.

\subsubsection{Inversão das Velocidades de $C$ e $U$ do Arranjo}

Esta etapa consiste na inversão das curvas de dispersão de C e U, onde obtemos modelos de velocidade da onda S. As curvas de dispersão das velocidades de grupo ou fase são uma função $G(T)$, sendo esta:

$$
G(T)=g(\alpha, \beta, \rho, h)
$$

T é o período, $\alpha$ é velocidade da onda longitudinal, $\beta$ é velocidade da onda transversal, $\rho$ é a densidade do meio, h é a espessura da camada.

A inversão das curvas de dispersão trata-se de um problema de vários parâmetros, no entanto para simplificá-lo fizemos $\rho$ calculada por meio da velocidade da onda $\mathrm{P}$, através da equação (2.5) (Christensen e Mooney, 1995).

$$
\rho=5,456-\frac{16,79}{v_{p}}
$$

A razão $\left(\frac{v_{p}}{v_{s}}\right)$ é constante e as espessuras são fixadas, tornando o problema dependente somente da velocidade da onda $\mathrm{S}$ :

$$
G(T)=g(\beta)
$$

A resolução do problema de inversão de $\mathrm{G}(\mathrm{T})$ é feita através da linearização a partir de um modelo inicial, para um modelo final, a diferença entre velocidades de G observadas 
e teóricas para um período específico T (Herrmann e Ammon, 2002) é representada pela equação 2.7 .

$$
\Delta G(T)=\frac{\partial G(T)}{\partial \beta_{1}} \Delta \beta_{1}+\ldots+\frac{\partial G(T)}{\partial \beta_{j}} \Delta \beta_{j}
$$

$\frac{\partial G(T)}{\partial \beta}$ é a derivada parcial da velocidade (U ou $\mathrm{C}$ ), com relação à velocidade da onda $\beta$ e $\Delta \beta$ é a variação da velocidade da onda $\mathrm{S}$ em uma camada específica.

Foi realizada a inversão separada da Rayleigh e da Love, pois para que haja inversão conjunta, é necessário anisotropia.

O surf96 programa de Herrmann e Ammon (2002) foi usado em nossa inversão. O programa necessita de um modelo inicial sem variações abruptas de velocidade, para que a convergência seja mais rápida e os resultados finais sejam mais confíaveis. Foram usados seis modelos iniciais e obtidos seis modelos finais (três para cada onda de superfície). A comparação entre os modelos iniciais e finais esta no capítulo de resultados.

\subsection{Dados}

Foram usados 24 eventos, no período do segundo semestre de 2016 ao segundo semestre de 2018. Os sismos possuem magnitudes maiores que 5,5, com as suas profundidades variando entre 10 a $147 \mathrm{~km}$. As informações destes eventos podem ser observadas na Tabela 2.2 e sua distribuição epicentral, na Figura (2.14).

Desses 24 sismos foram obtidas um total de 45 curvas de dispersão. Para a onda Rayleigh foram obtidas: 24 de fase no modo fundamental, 5 para o primeiro modo superior de vibração e 8 curvas de velocidade de grupo do $\operatorname{arranjo,~Figuras(2.15~a~2.17).~Para~a~}$ onda Love: 8 curvas de velocidade de fase no modo fundamental Figura (2.18). 
Tabela 2.2 - Informações dos Eventos

\begin{tabular}{|c|c|c|c|c|c|c|c|}
\hline \multicolumn{8}{|c|}{ Eventos } \\
\hline \# & Id & Lon. & Lat. & Prof. (km) & Data e Hora & Mag. & Epicentro \\
\hline 0 & coty & -74.68 & 3.38 & 32.0 & 2017_02_06_13_02_44 & $5.7 \mathrm{M}$ & Colômbia \\
\hline 1 & iacr & -71.80 & -32.95 & 20.0 & 2017_04_24_21_38_26 & $6.9 \mathrm{M}$ & Próximo à Costa Central Chile \\
\hline 2 & igyo & -71.89 & -33.21 & 20.0 & 2017_04_28_15_30_05 & $5.9 \mathrm{M}$ & Próximo à Costa Central Chile \\
\hline 3 & $\operatorname{igzs}$ & -71.76 & -33.04 & 14.0 & 2017_04_28_16_05_54 & $5.7 \mathrm{M}$ & Próximo à Costa Central Chile \\
\hline 4 & jdmf & -25.73 & -56.45 & 10.0 & 2017_05_10_23_23_35 & $6.3 \mathrm{M}$ & Região Sul das Ilhas Sandwich \\
\hline 5 & lkex & -71.63 & -31.50 & 26.0 & 2017_06_12_02_43_26 & $5.8 \mathrm{M}$ & Próximo à Costa Central Chile \\
\hline 6 & $\mathrm{mspc}$ & -80.42 & -25.78 & 10.0 & 2017_06_30_22_29_43 & $6.1 \mathrm{M}$ & Próximo à Costa do Equador \\
\hline 7 & opoo & -49.33 & 13.40 & 10.0 & 2017_07_27_17_53_25 & $5.8 \mathrm{M}$ & Norte do Oceano Atlântico \\
\hline 8 & puob & -74.47 & -10.72 & 10.0 & 2017_08_13_16_51_22 & $5.6 \mathrm{M}$ & Central Peru \\
\hline 9 & ribw & -25.95 & -57.81 & 147.0 & 2017_09_04_08_07_48 & $6.1 \mathrm{M}$ & Região Sul das Ilhas Sandwich \\
\hline 10 & rpdi & -93.84 & 14.91 & 60.0 & 2017_09_08_04_49_18 & $8.0 \mathrm{M}$ & Próximo à Costa de Chiapas, Mexico \\
\hline 11 & tvsu & -69.57 & -18.50 & 63.0 & 2017_10_10_06_32_18 & $6.3 \mathrm{M}$ & Norte do Chile \\
\hline 12 & twrg & 8.36 & -54.10 & 10.0 & 2017_10_10_18_53_34 & $5.9 \mathrm{M}$ & Região da Ilha Bouvet \\
\hline 13 & $\mathrm{xkxm}$ & -23.47 & -10.05 & 10.0 & 2017_11_30_06_32_50 & $6.2 \mathrm{M}$ & Cordilheira Central do Atlântico \\
\hline 14 & znwd & -69.47 & -19.16 & 10.0 & 2017_12_30_08_20_39 & $5.8 \mathrm{M}$ & Norte do Chile \\
\hline 15 & aylz & -74.15 & -15.75 & 43.0 & 2018_01_14_09_18_50 & $7.3 \mathrm{M}$ & Próximo à Costa do Peru \\
\hline 16 & bqpy & -69.23 & -20.17 & 10.0 & 2018_01_24_07_45_54 & $5.6 \mathrm{M}$ & Norte do Chile \\
\hline 17 & aqre & -83.79 & 17.26 & 10.0 & 2018_01_10_02_51_30 & $7.1 \mathrm{M}$ & Norte de Honduras \\
\hline 18 & gzrg & -71.31 & -30.95 & 40.0 & 2018_04_10_10_19_32 & $6.4 \mathrm{M}$ & Próximo à Costa Central Chile \\
\hline 19 & pvjd & -25.35 & -58.34 & 10.0 & 2018_08_14_03_29_48 & $6.5 \mathrm{M}$ & Região Sul das Ilhas Sandwich \\
\hline 20 & rncq & -78.29 & -2.26 & 60.0 & 2018_09_07_02_12_04 & $6.3 \mathrm{M}$ & Equador \\
\hline 21 & tabs & 119.93 & -0.20 & 10.0 & 2018_09_28_10_02_43 & $7.3 \mathrm{M}$ & Minahassa Península, Sulawesi \\
\hline 22 & tptu & -72.93 & 20.06 & 12.0 & 2018_10_07_00_11_48 & $5.9 \mathrm{M}$ & Região do Haiti \\
\hline 23 & $\mathrm{xcsc}$ & -89.04 & 11.78 & 10.0 & 2016_11_24_18_43_46 & $7.0 \mathrm{M}$ & Distante da Costa da América Central \\
\hline
\end{tabular}




\section{Eventos}

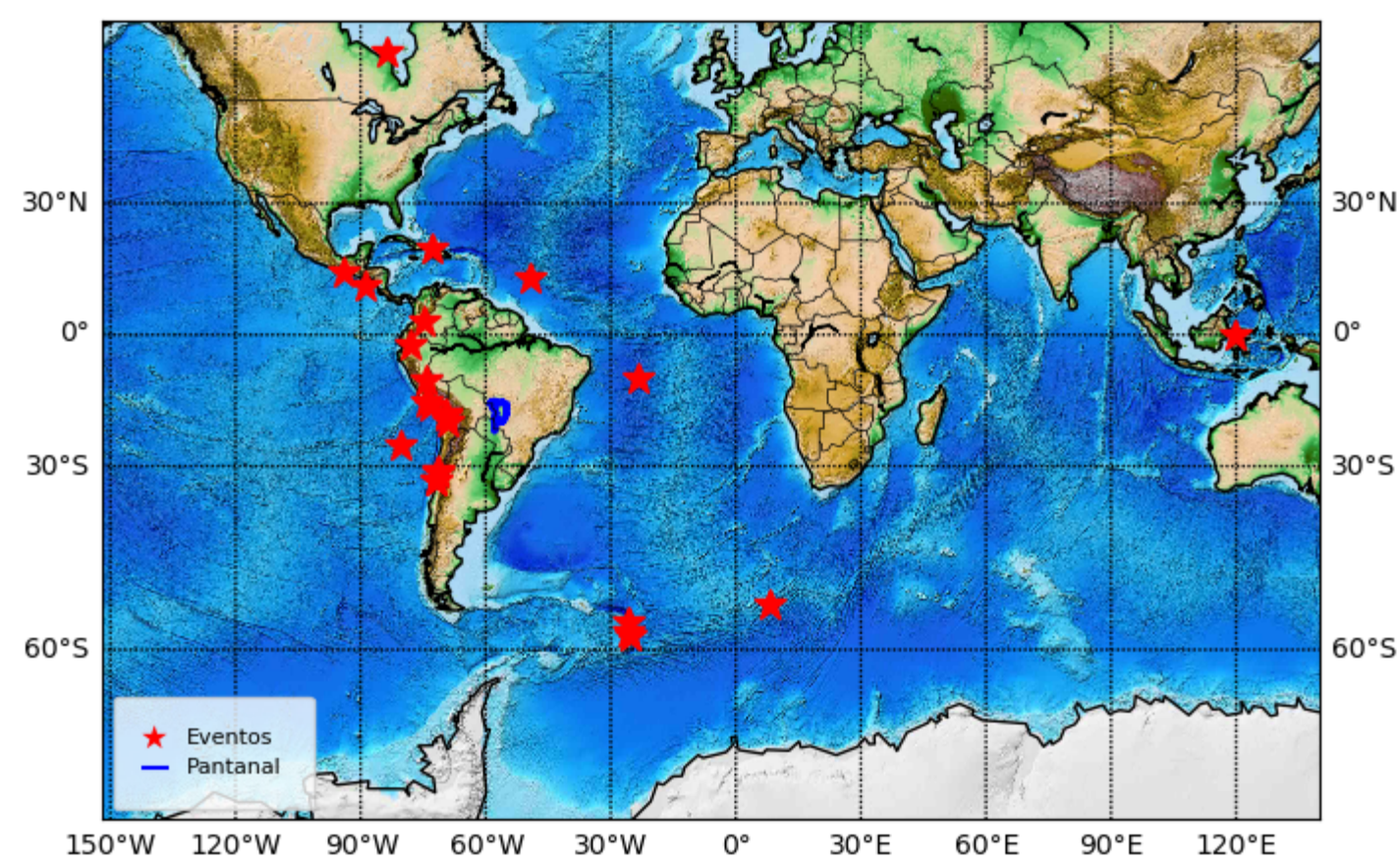

Figura 2.14: Epicentros dos eventos trabalhados. Estrelas em vermelho são os eventos e a área circulada em azul é a Bacia do Pantanal.

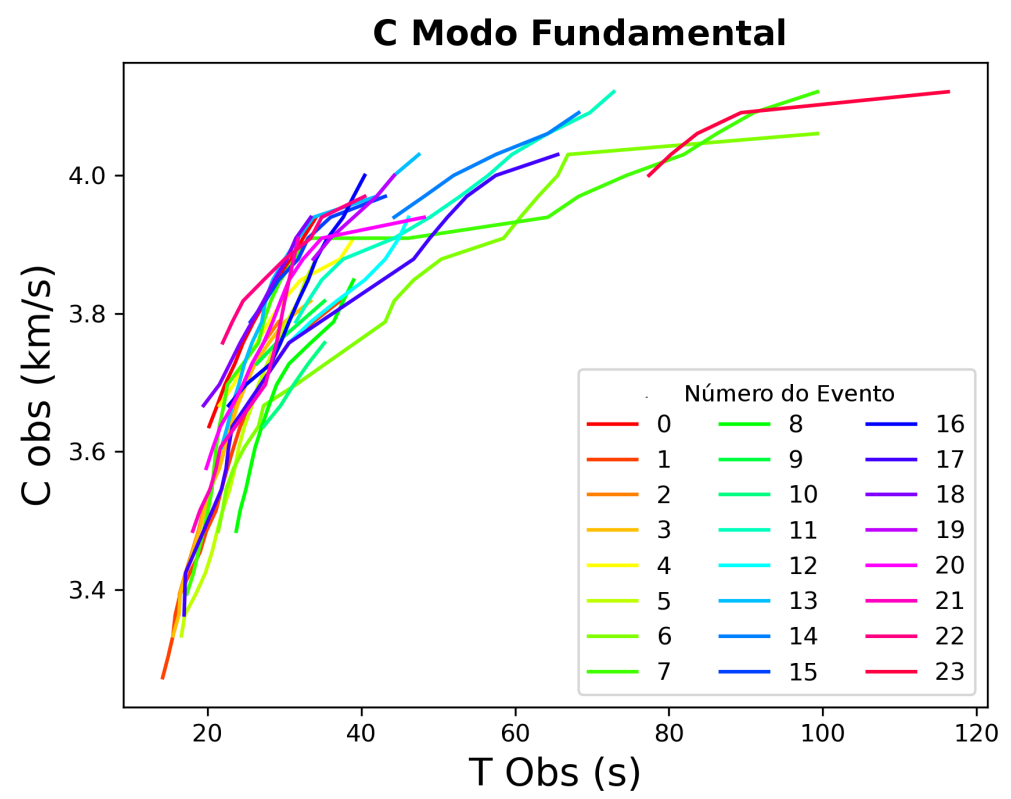

Figura 2.15: Todas as curvas de dispersão de Velocidade de fase para onda Rayleigh, cada cor representa uma evento, sendo a numeração de cada evento igual á Tabela 2.2. 


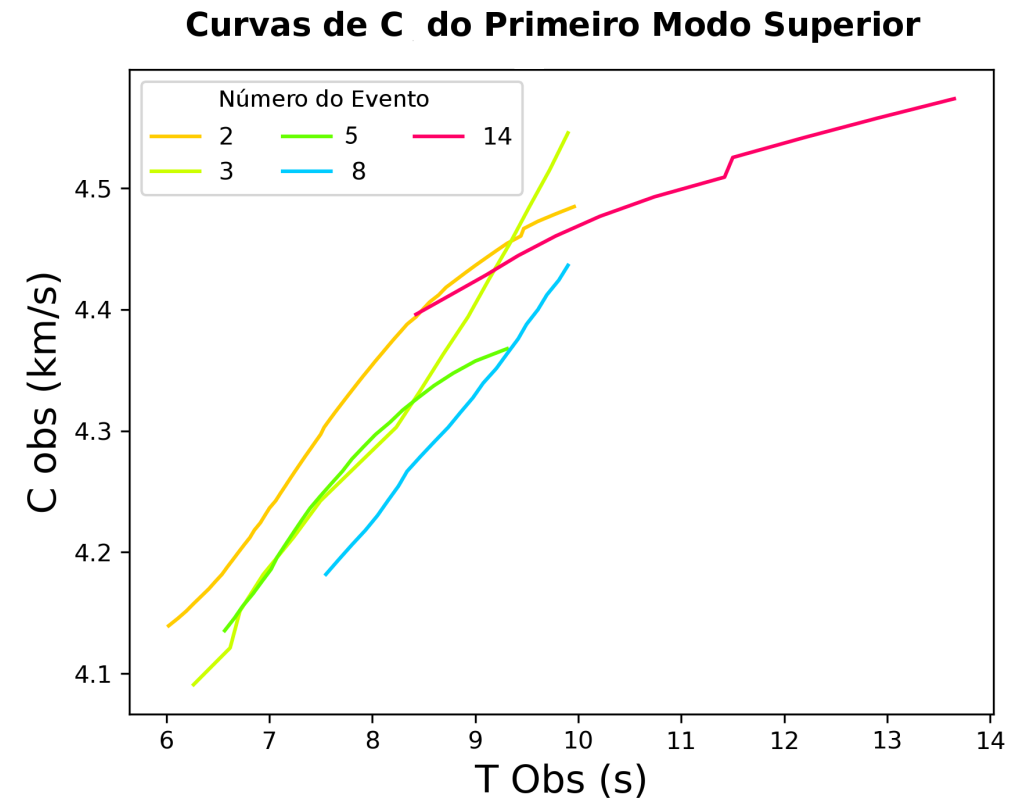

Figura 2.16: Curvas de C (km/s) para o primeiro modo de vibração da Rayleigh. Cada cor representa a numeração de cada evento que foi possível obter as velocidade, de acordo com a Tabela 2.2.

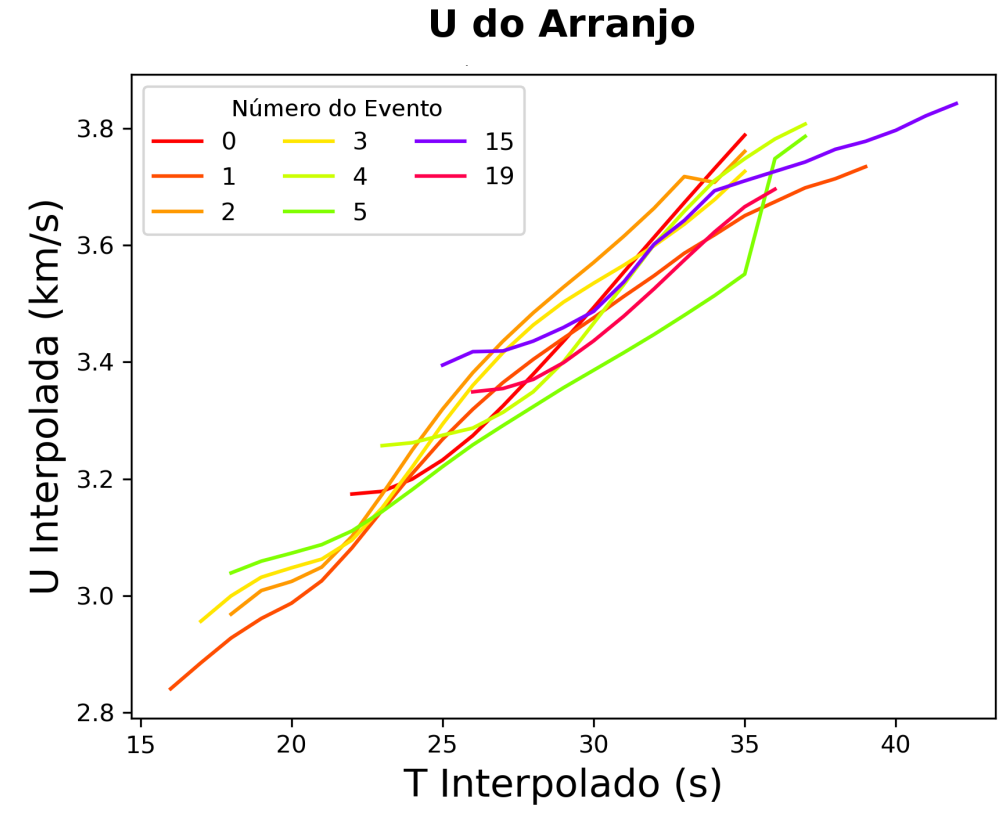

Figura 2.17: Curvas de U $(\mathrm{km} / \mathrm{s})$ do arranjo. Cada cor representa a numeração de cada evento que foi possível obter as curvas velocidade de grupo da Rayleigh, de acordo com a Tabela 2.2.

Para se obter $U_{\text {media }}$ do arranjo de estações dependemos que as estações estejam bem localizadas entre si. No entanto, para períodos maiores que 42 segundos, não era possível 
determinar as incertezas e em alguns casos nem as velocidades. Isso pode estar relacionado ao fato de que as estações não estarem bem alocadas. Outro fator importante é que embora o arranjo é composto por 14 estações, o valor máximo de estações usadas por evento foram de 12. Estações como CCRS, PANT e POCN, ambas pertencentes a rede XC, apresentaram nas análises, sismogramas com defeitos nas componentes, ruidosos ou não registraram o evento. As estações do arranjo que foram usadas para cada evento trabalhado encontram-se no apêndice $\mathrm{A}$.

Para a Rayleigh, as curvas de C (km/s) no modo lfundamental apresentam períodos entre 15 a 116 segundos e velocidades entre 3,3 a $4,12 \mathrm{~km} / \mathrm{s}$. Já para o primeiro modo de vibração os períodos foram entre 7 a 13 segundos, com velocidades de 4,2 a $4.5 \mathrm{~km} / \mathrm{s}$. As de grupo apresentaram períodos de 16 a 42 e suas velocidades variaram entre 2,84 a 3,84 $\mathrm{km} / \mathrm{s}$.

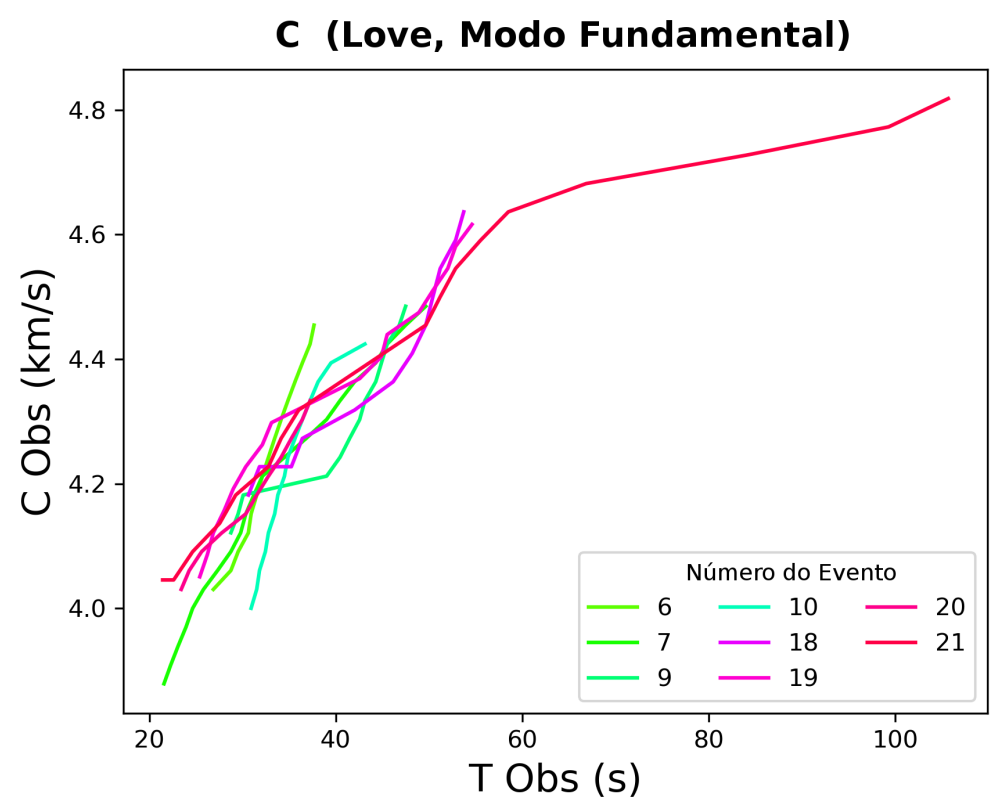

Figura 2.18: Curvas de C $(\mathrm{km} / \mathrm{s})$ para o modo fundamental para onda Love. Cada cor representa a numeração de cada evento que foi possível obter as velocidade, de acordo com a Tabela II.O eixo y é a velocide de fase observada e o x período observado.

Para onda Love, seus períodos variam entre 22 a 105 segundos, sendo suas velocidades entre 3,97 a 4,81. Não foi possível usar as curvas de $\mathrm{U}(\mathrm{km} / \mathrm{s})$, visto que as curvas obtidas não ajustavam.

Foi observado que ao inverter todas as curvas juntas de cada onda de superfície, aumentava o tempo da inversão, assim como, sua imprecisão. Dessa forma, as curvas de C 
$(\mathrm{km} / \mathrm{s})$ foram interpoladas para períodos inteiros, em seguida foram calculadas as médias das velocidades para cada período e seus devios padrão, de cada tipo e modo das ondas trabalhadas (figura 2.19).

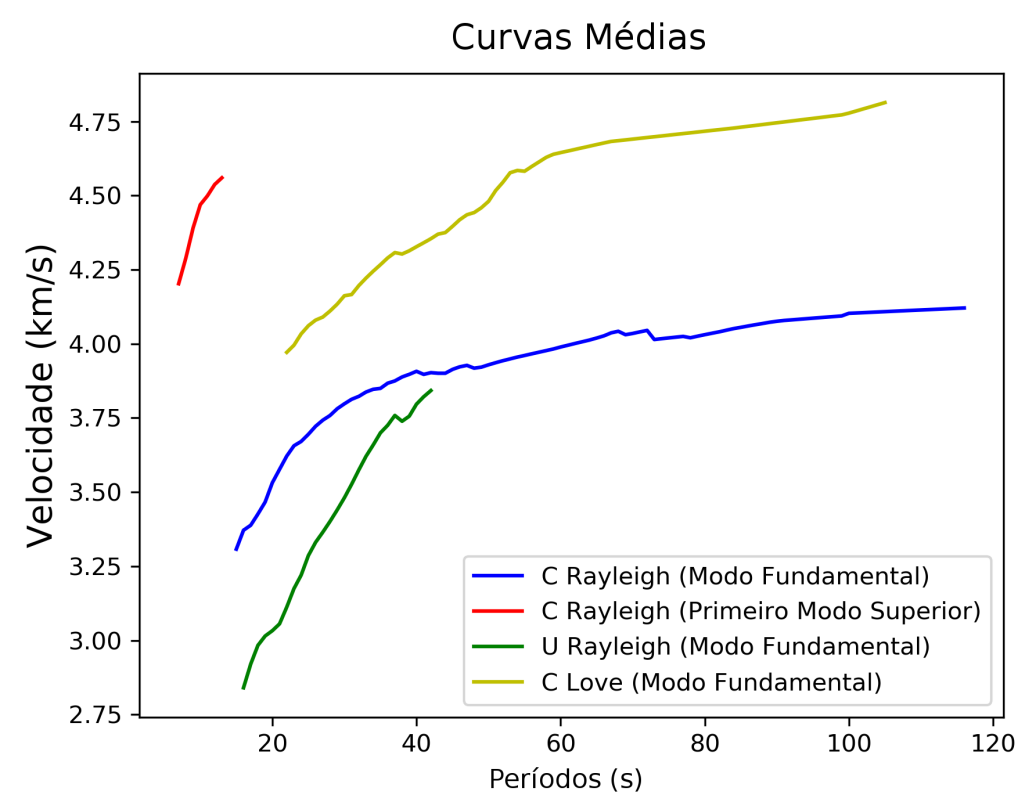

Figura 2.19: Curvas médias C $(\mathrm{km} / \mathrm{s})$ e U $(\mathrm{km} / \mathrm{s})$ para os modos da onda Rayleigh e Love. O eixo y é a velociade de fase observada e o x período observado. 
Capítulo 3

\section{Resultados e Discussões}

\subsection{Inversões Para Onda Love}

\subsubsection{Modelo I}

Os primeiros $100 \mathrm{~km}$ do modelo inicial da primeira inversão, foram construídos com 20 camadas de $5 \mathrm{~km}$ de espessura, após isso usamos camadas de $10 \mathrm{~km}$, até totalizar $190 \mathrm{~km}$ de profundidade. Sua velocidade inicial é de $3,10 \mathrm{~km} / \mathrm{s}$ e apresenta variações de $0,05 \mathrm{~km} / \mathrm{s}$ até os primeiros $30 \mathrm{~km}$ de profundidade, a partir desse ponto as variações passam para $0,1 \mathrm{~km} / \mathrm{s}$, em $85 \mathrm{~km}$ as variações voltam para $0,05 \mathrm{~km} / \mathrm{s}$. Sendo a velocidade final de 5,70 $\mathrm{km} / \mathrm{s}$.

Embora a inversão não possua muitas curvas de dispersão se comparadas com a onda Rayleigh, houve um ajuste aceitável. Após 40 iterações, seu desvio padrão foi no entorno de $\pm 0,0343 \mathrm{~km} / \mathrm{s}$ (Figura 3.1). É possível observar que a Descontinuidade de Mohorovicic deva estar provavelmente no intervalo de 35 a $40 \mathrm{~km}$. Em 120 km há o início da redução na velocidade da onda SH, sendo a velocidade nessa profundidade de 4,4412 km/s. A variação é 1,3\% menor do que o observado pelo modelo IASP91 $\left(V_{s}=4,492\right)$. Em $150 \mathrm{~km}$ a variação torna-se $2,8 \%$.

\subsubsection{Modelo II}

O modelo inicial da segunda inversão foi construído com um total de 12 camadas de $5 \mathrm{~km}$ e 19 camadas de $10 \mathrm{~km}$, sendo a profundidade final de $250 \mathrm{~km}$. Este modelo possui velocidades mais altas que o primeiro. A velocidade inicial é de $3,30 \mathrm{~km} / \mathrm{s}$ e as variações da velocidade por camada são de $0,1 \mathrm{~km} / \mathrm{s}$ até aos $35 \mathrm{~km}$, em seguida passam para $0,05 \mathrm{~km} / \mathrm{s}$ até $40 \mathrm{~km}$ e novamente passam para $0,1 \mathrm{~km} / \mathrm{s}$ até profundidade de $60 \mathrm{~km}$, essas variações 

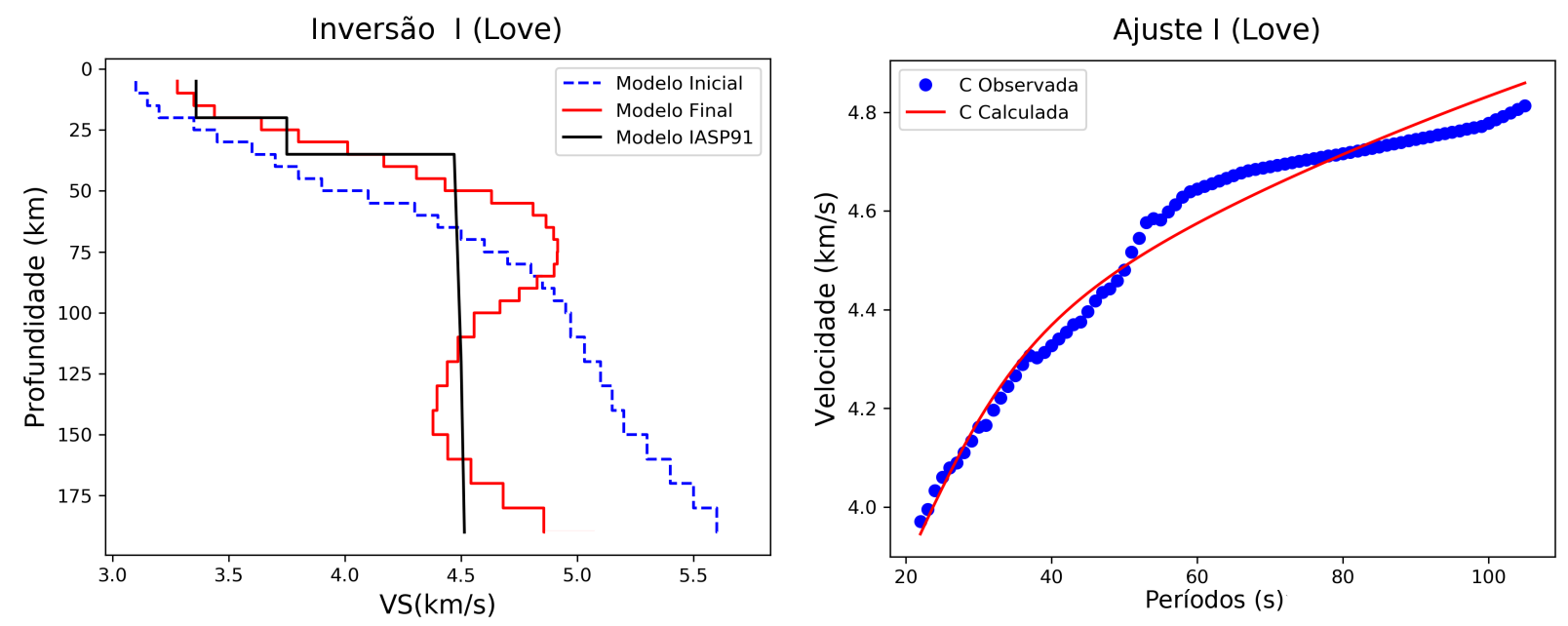

Figura 3.1: À esquerda está o primeiro modelo inicial para a Love em azul e o modelo final em vermelho, após 40 iterações e o modelo IASP91 em preto, usado para comparação. À direita temos o ajuste da curva de dispersão de $\mathrm{C}(\mathrm{km} / \mathrm{s})$. Onde os círculos em azul representam o dado observado e a reta em vermelho o dado calculado.

continuam até chegar a $250 \mathrm{~km}$ com a velocidade de $5,80 \mathrm{~km} / \mathrm{s}$.

Aplicamos 18 iterações, houve um ajuste significativo e seu desvio padrão foi de $\pm 0,056$ $\mathrm{km} / \mathrm{s}$ (Figura 3.2). Novamente pode-se observar que possivelmente a Moho esteja entre 35 a $40 \mathrm{~km}$ de profundidade. Por volta de $120 \mathrm{~km}$ há uma diminuição na velocidade da onda SH de $4,65 \mathrm{~km} / \mathrm{s}$, no entanto este resultado é $2,79 \%$ maior do que o observado pelo modelo IASP91. Por volta de $150 \mathrm{~km}$ a $V_{s}$ é semelhante ao modelo usado para comparação.
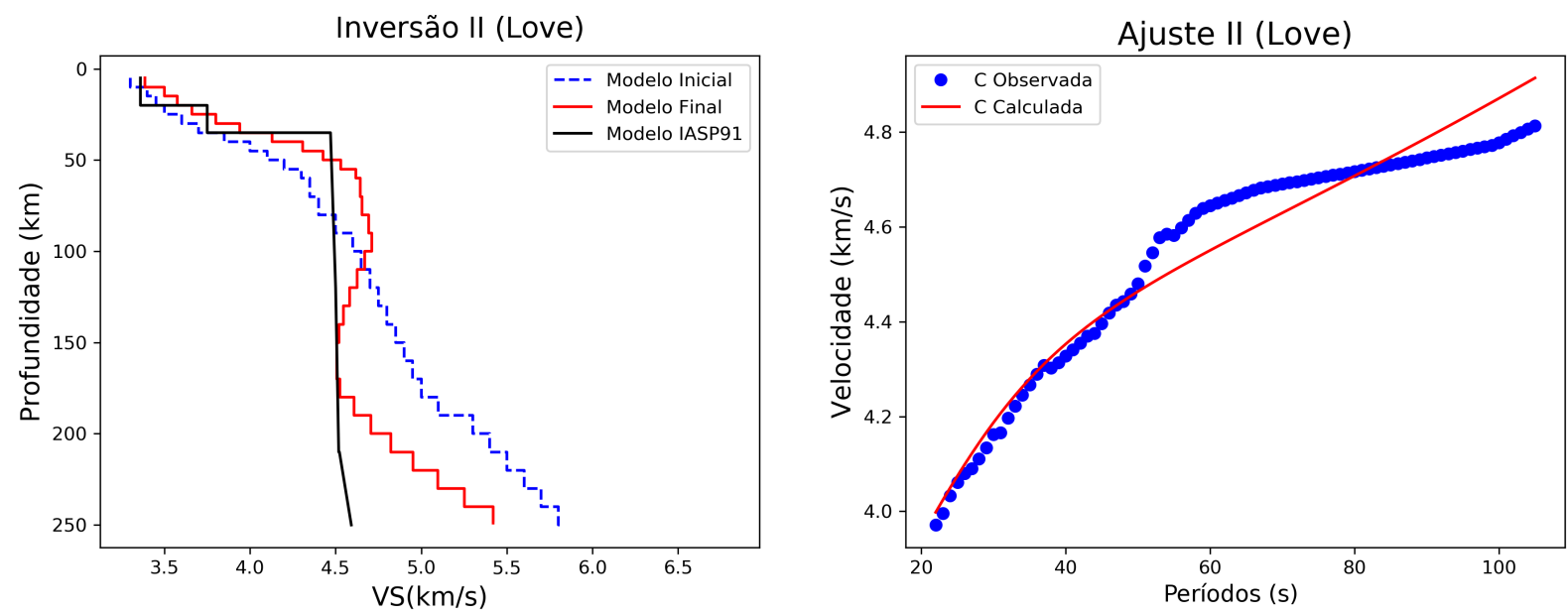

Figura 3.2: À esquerda temos o segundo modelo inicial da Love em azul e o modelo final em vermelho, após 18 iterações e o modelo IASP91 em preto, usado para comparação. À direita temos o ajuste da curva de dispersão de C. Onde os círculos em azul representam o dado observado e a reta em vermelho o dado calculado. 


\subsubsection{Modelo III}

O modelo III possui a mesma construção em camadas que o modelo I, sua diferença relaciona-se com as variações de velocidade por camada. Ele inicia com a velocidade de $3,10 \mathrm{~km} / \mathrm{s}$, sofrendo alterações de 0,05 até os $30 \mathrm{~km}$, em seguida sofre uma mudança mais abrupta para $0,15 \mathrm{~km}$ em $35 \mathrm{~km}$ e depois passa para $0,1 \mathrm{~km} / \mathrm{s}$ até os $80 \mathrm{~km}$ de profundidade e, por conseguinte passa a sofrer variações mais suaves de 0,02 a 0,03 até os $190 \mathrm{~km}$ de profundidade que apresenta uma $V_{s}=5,02$.

Aplicamos 40 iterações, seu desvio padrão foi de $\pm 0,0238 \mathrm{~km} / \mathrm{s}$ (Figura 3.3). O ajuste é significativo, é possível observar a queda na velocidade da $\mathrm{SH}$ por volta de $120 \mathrm{~km}$, contudo é $6 \%$ maior que o IASP91 e em $150 \mathrm{~km}$ cai para $5 \%$.
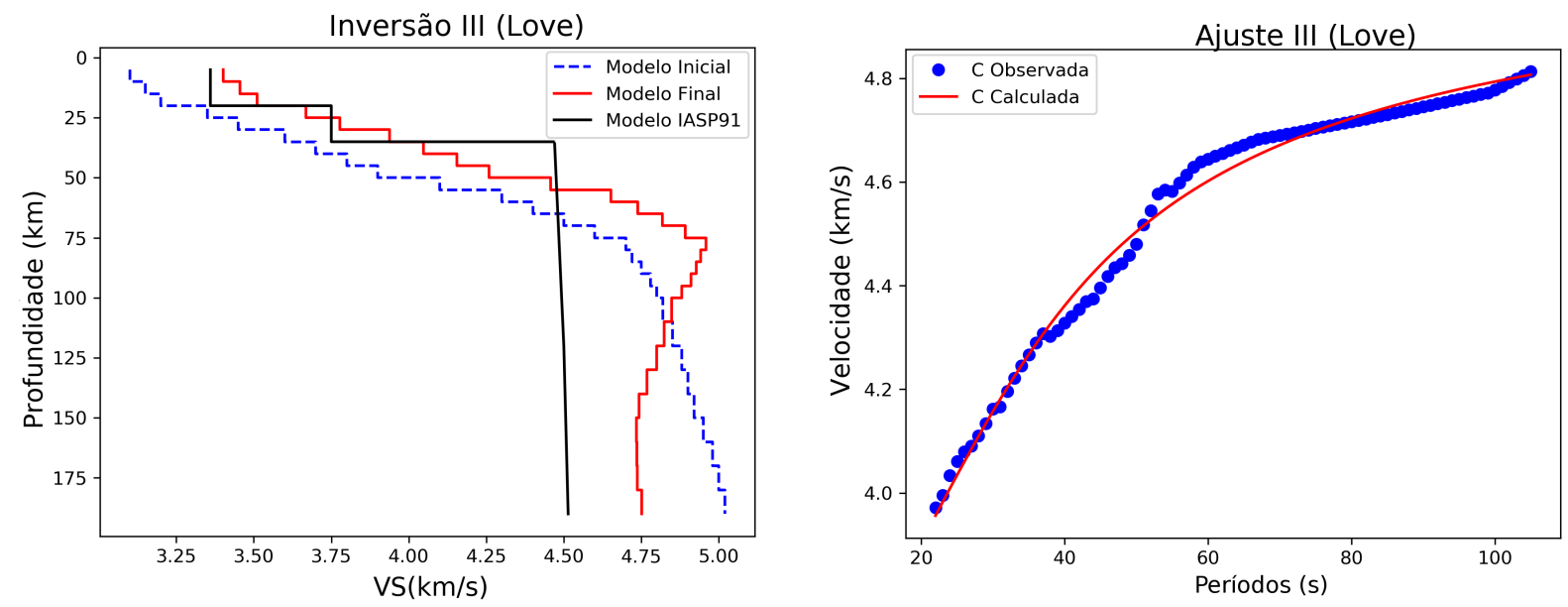

Figura 3.3: À esquerda temos o terceiro modelo inicial da Love em azul e o modelo final em vermelho, após 40 iterações e o modelo IASP91 em preto, usado para comparação. À direita temos o ajuste da curva de dispersão de C. Onde os círculos em azul representam o dado observado e a reta em vermelho o dado calculado.

Como observado, as inversões para a onda Love são anômalas, visto que conforme alterações nos modelos iniciais houve uma gradativa mudança nos modelos finais para a onda SH, à razão principal é devido a pouca quantidade de curvas de dispersão utilizadas para a inversão. As velocidades $U$ obtidas para onda Love no arranjo geraram um mau ajuste, dessa forma optamos por não inseri-las na inversão final.

\subsection{Inversões Para Onda Rayleigh}

Os modelos iniciais I e III possuem profundidade máxima de até $190 \mathrm{~km}$ e foram utilizadas 40 iterações, enquanto que o II têm $250 \mathrm{~km}$ e utilizamos 18 iterações. Suas 
velocidades iniciais variam de 3,1 a $3,6 \mathrm{~km} / \mathrm{s}$, e suas velocidades máximas estão entre 4,55 a $5,60 \mathrm{~km} / \mathrm{s}$. O processo de construção destes modelos é semelhante aos da onda Love. Dentre os modelos apresentados o I apresenta maior alteração de velocidades por camada. Ambos apresentam um gradiente positivo de velocidade.

Os desvios padrões são respectivamente: $\pm 0,034 \mathrm{~km} / \mathrm{s}, \pm 0,018$ e $\pm 0,059 \mathrm{~km} / \mathrm{s}$, os núcleos de sensibilidade mostram que a resolução máxima do modelo está por volta de $150 \mathrm{~km}$. Como observado antes, variações mínimas na velocidade em $\mathrm{C}$ geram grandes variações em U, Figuras (3.4 a 3.6). O Surf96 utiliza as velocidades de U para assim calcular os núcleos de sensibilidade, por meio da equação (2.1), devido a isto, não foi possível obter os núcleos de sensibilidade para a onda Love. Embora possuamos períodos de U de até 44 segundos, o programa utilizado extrapola para os períodos maiores.
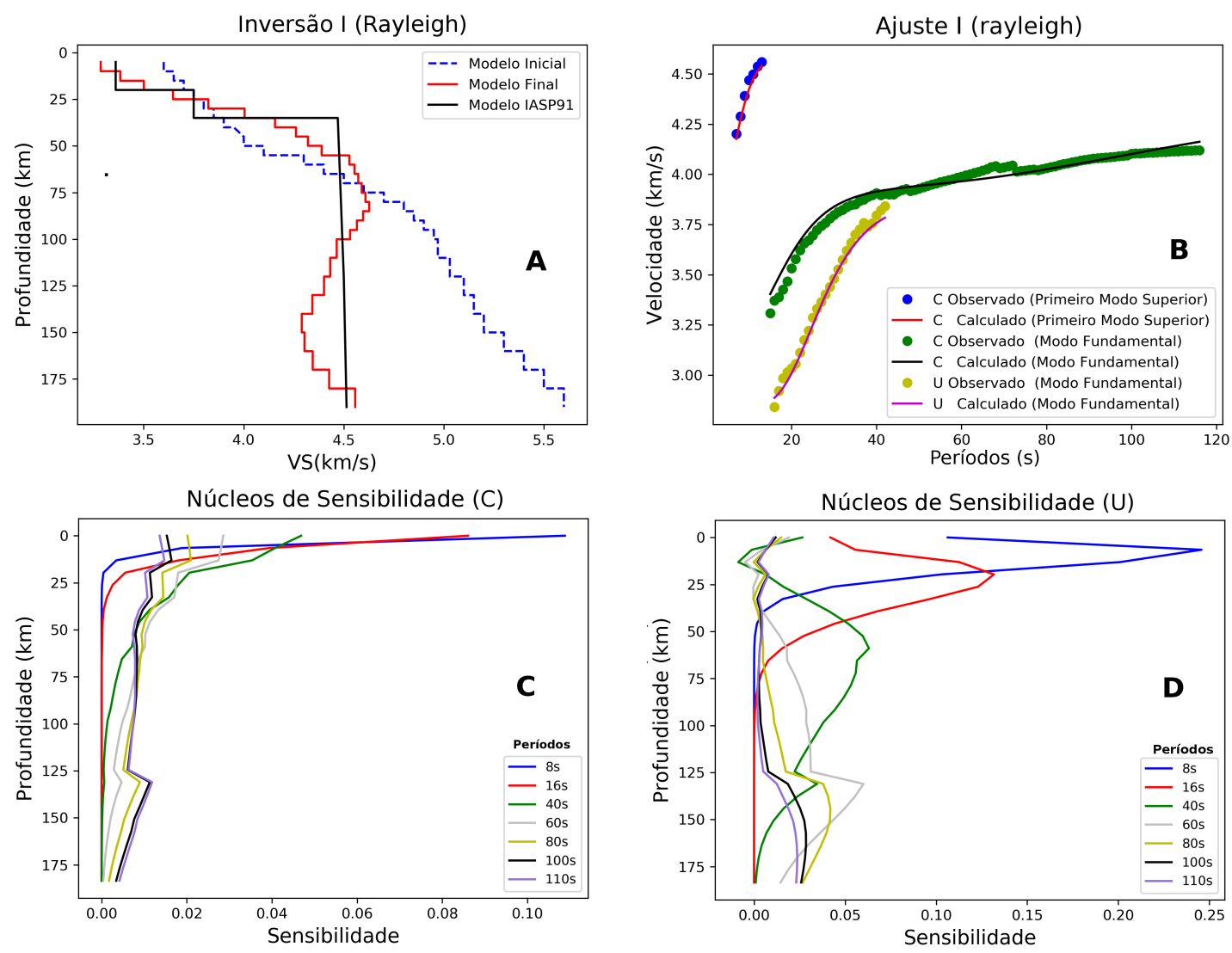

Figura 3.4: A: Primeiro modelo inicial da Rayleigh em azul e o modelo final em vermelho, após 40 iterações e o modelo IASP91 em preto, usado para comparação, desvio padrão de $\pm 0,034 \mathrm{~km} / \mathrm{s}$. B: ajuste das curvas de dispersão de $\mathrm{C}$ e $\mathrm{U}(\mathrm{km} / \mathrm{s})$. Onde os círculos em verde representam $\mathrm{C}$ (observada) e a reta em preto $\mathrm{C}$ (calculada), do modo fundamental. Os pontos em azul são C (observada) para o primeiro modo de vibração, e a reta em vermelho C (calculada). Já os círculos em amarelo representam U (observada) e a reta em magenta U (calculada), do modo fundamental. C e D: Núcleos de sensibilidade de U e C para a onda Rayleigh. 

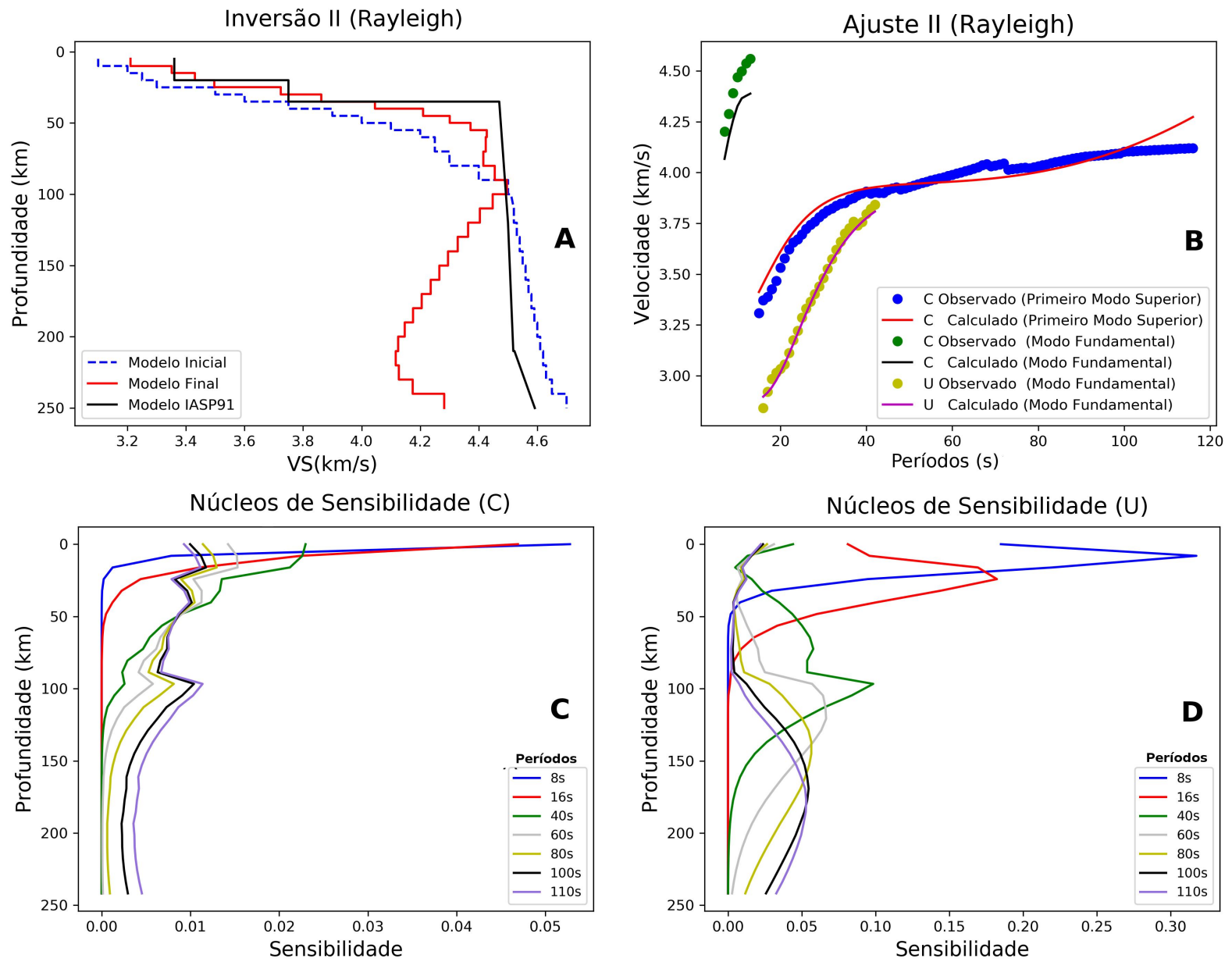

Figura 3.5: A: Segundo modelo inicial da Rayleigh em azul e o modelo final em vermelho, após 18 iterações e o modelo IASP91 em preto, usado para comparação, desvio padrão de $\pm 0,018$. B: ajuste das curvas de dispersão de $\mathrm{C}$ e $\mathrm{U}(\mathrm{km} / \mathrm{s})$. Onde os círculos em verde representam C (observada) e a reta em preto C (calculada), do modo fundamental. Os pontos em azul são C (observada) para o primeiro modo de vibração, e a reta em vermelho $\mathrm{C}$ (calculada). Já os círculos em amarelo representam U (observada) e a reta em magenta $\mathrm{U}$ (calculada), do modo fundamental. C e D: Núcelos de sensibilidade de U e C para a onda Rayleigh. 

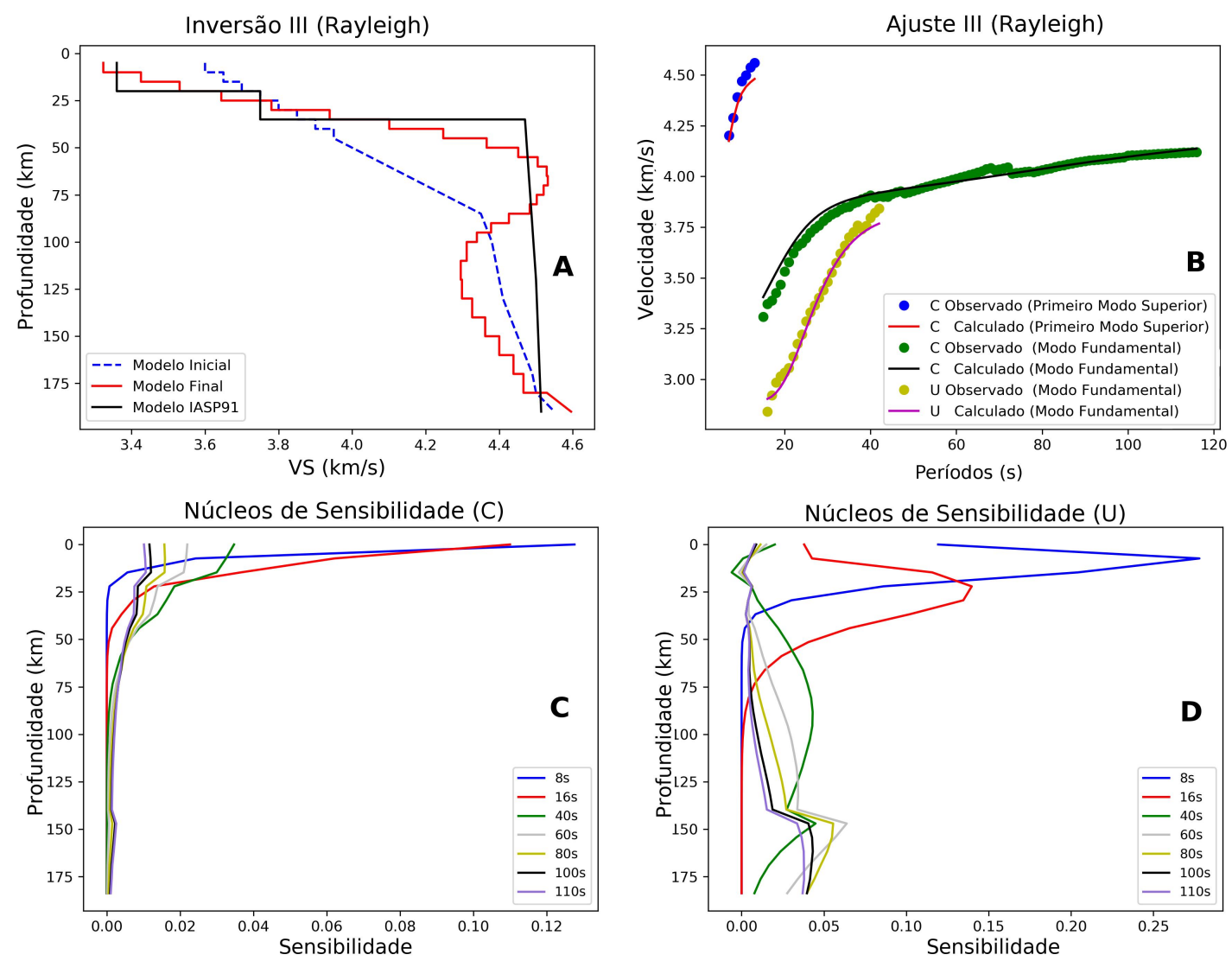

Figura 3.6: A: Terceiro modelo inicial da Rayleigh em azul e o modelo final em vermelho, após 40 iterações e o modelo IASP91 em preto, usado para comparação, desvio padrão de $\pm 0,059 \mathrm{~km} / \mathrm{s}$. B: ajuste das curvas de dispersão de $\mathrm{C}$ e $\mathrm{U}(\mathrm{km} / \mathrm{s})$. Onde os círculos em verde representam $\mathrm{C}$ (observada) e a reta em preto C (calculada), do modo fundamental. Os pontos em azul são C (observada) para o primeiro modo de vibração, e a reta em vermelho $\mathrm{C}$ (calculada). Já os círculos em amarelo representam U (observada) e a reta em magenta U (calculada), do modo fundamental. C e D: Núcelos de sensibilidade de U e C para a onda Rayleigh.

Em $110 \mathrm{~km}$ há uma zona de baixa de velocidade com variações de 1,3 a 4,3\% menores em relação ao modelo que estamos comparando, sendo os modelos I e II os que apresentam menor variação na velocidade. Em $150 \mathrm{~km}$ esta variação torna-se maior para I e II e menor para III, sendo de 3,2 a 5,3\%. A comparação de todos modelos finais apresentados está na Figura (3.7).

Segundo Rivadeneyra-Vera et al. (2019), na borda leste da BSP há uma região com a crosta com espessura entre 30 a $35 \mathrm{~km}$. Já ao longo da região oeste, a espessura da crosta situa-se entre 38 a $43 \mathrm{~km}$. Os modelos apresentados são uma média das curvas de dispersão das estações que estão alocadas próximas à área de estudo, a Moho da Bacia em nosso caso, situa-se entre de 35 a $40 \mathrm{~km}$. 


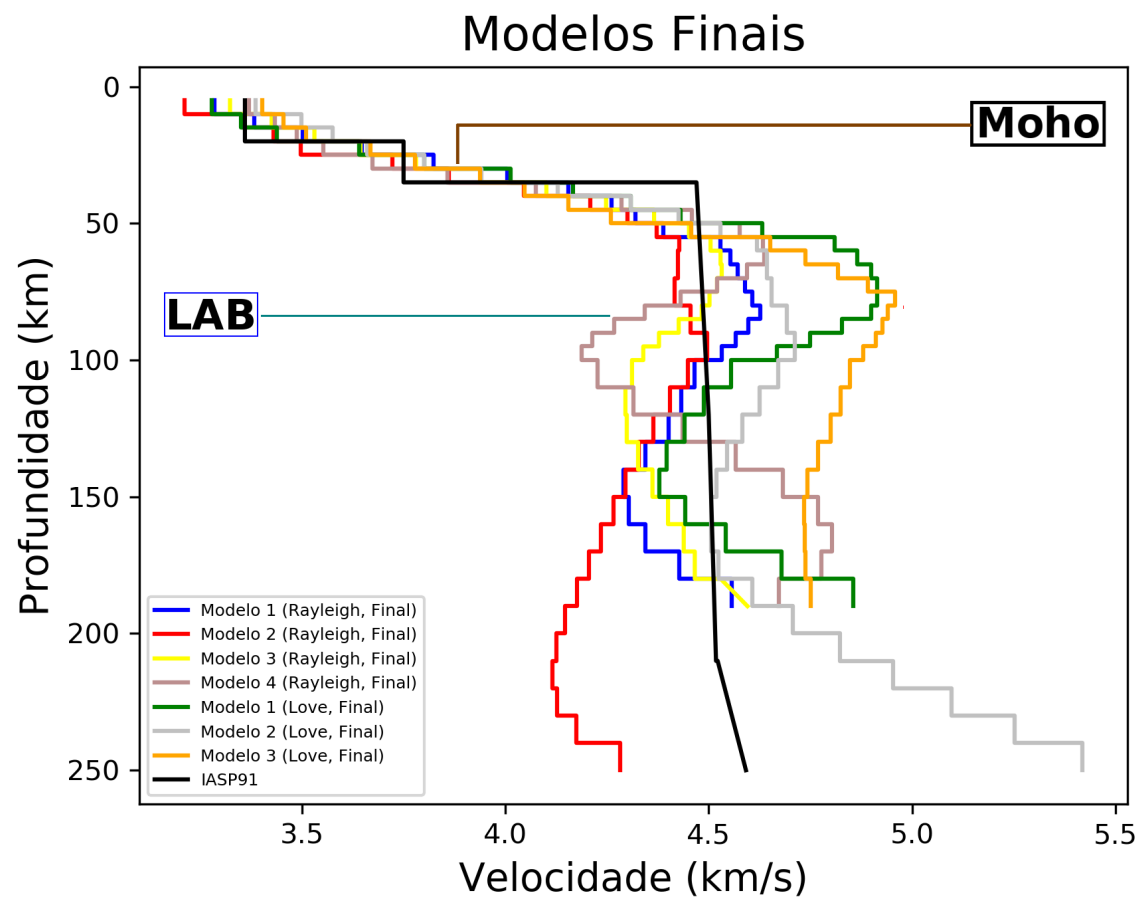

Figura 3.7: Comparação entre os modelos finais da Rayleigh e da Love. A Descontinuidade de Mohorovicic esta entre 35 a $40 \mathrm{~km}$ e o Limite entre a Litsofera e Astenosfera inicia-se entre $110 \mathrm{~km}$.

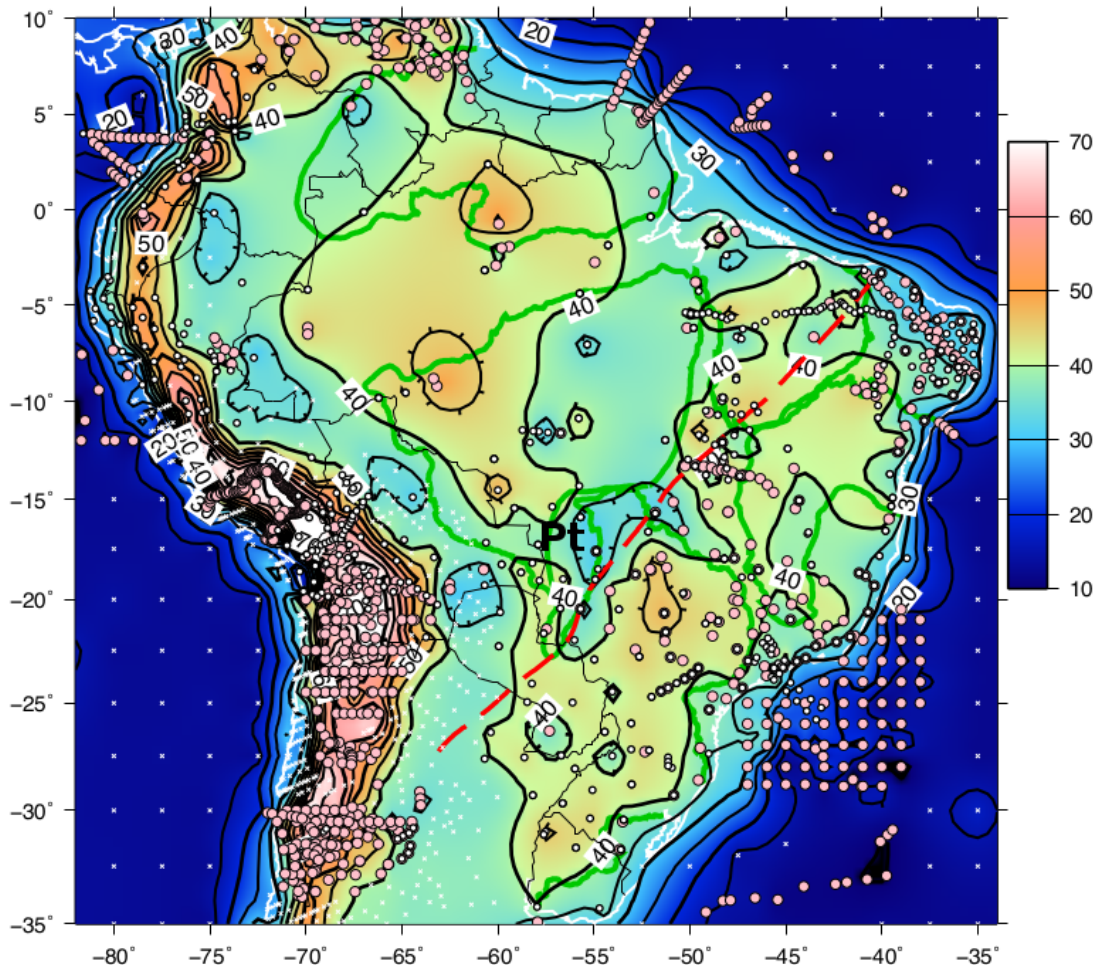

Figura 3.8: Mapa atualizado da espessura da crosta na América do Sul. Círculos vermelhos são dados de Assumpção et al. (2013). Os círculos brancos são os dados atuais, proveniente das análises das redes XC e RSBR. Imagem retirada de Rivadeneyra-Vera et al. (2019). 
Segundo Eaton et al. (2009) uma definição para litosfera é: Camada limite mecânica e rígida na superfície da Terra, sendo sustentada por uma camada mais fraca, sendo esta denominada astenosfera, que possui a característica de deformação plástica generalizada em escalas de tempo de dezenas de milhares de anos e entre a litosfera e a astenosfera há um limite (LAB).

O LAB constitui, portanto, uma zona de desprendimento que compreende o tipo mais extenso de limite de placa no planeta, subjacente tanto nas regiões oceânicas quanto continentais. Conforme os métodos geofísicos aplicados para mensurar de forma indireta este limite, lhe são dados alguns nomes, como: MBL (Limite Mecânico), TBL (Limite Térmico), RBL (Limite Reológico), dentre outros Figura (3.9).
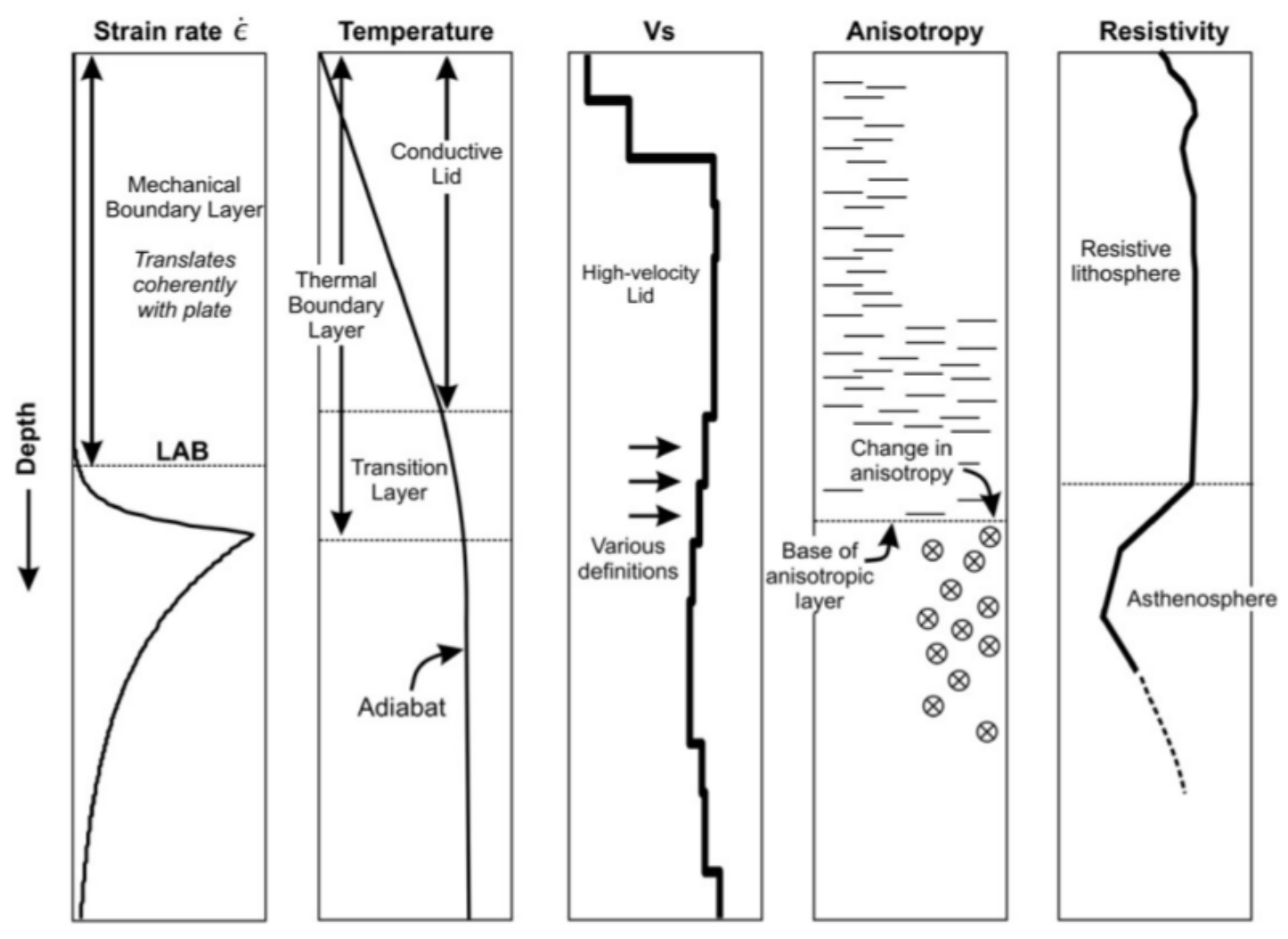

Figura 3.9: Observações geofísicas de alguns métodos utilizados para mensurar o LAB, como por exemplo, mudança na taxa de deformação; aumento na temperatura; região de baixa velocidade para a onda S (podendo estar relacionado com uma mudança tanto composicional, quanto térmica); alteração na anisotropia; diminuição na resistividade. Imagem retirada de Eaton et al. (2009).

Como mencionado antes em nossos modelos, foi observado a atenuação na velocidade da onda S. Levando em consideração o modelo I da Love e os demais da Rayleigh apresentaram uma perda de velocidade entre 110-120 km de profundidade. A diminuição na velocidade pode estar associada ao limite entre a litosfera e astenosfera. 
O modelo global para LAB de Plomerová et al. (2002) que utilizou anisotropia de ondas de superfície Figura (3.10), observa-se que este limite está entre 200 a 250 km em regiões de escudos e plataformas pré-cambrianas e para as regiões continentais Fanerozóicas situa-se em torno de $100 \mathrm{~km}$.

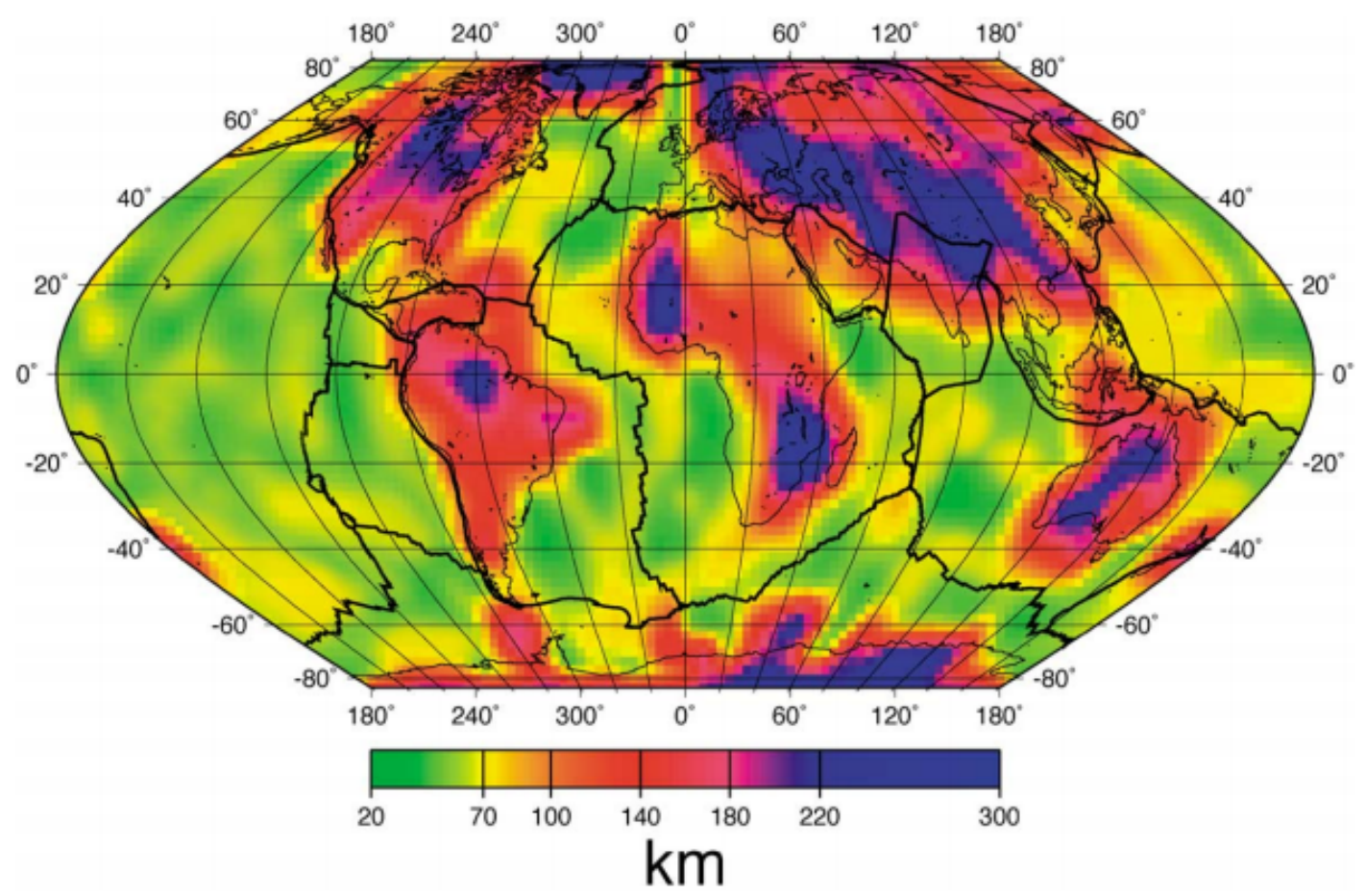

Figura 3.10: Modelo de profundidade global para o LAB. Imagem retirada de Plomerová et al. (2002).

Comparando os modelos com o CAM2016, sendo este um conjunto de modelos globais do manto superior, baseando-se na tomografia de ondas de superfície multímodo. Oriundo dos trabalhos de Cara e Leveque (1987), Debayle e M (2004), Debayle e Y (2006), (Debayle e Y, 2004) e (Ho et al., 2016). Neste modelo é possível observar que a espessura da litosfera na BSP está em torno de $108 \mathrm{~km}$ e a velocidade da SV é $2 \%$ maior que o modelo IASP91, Figura (3.11). 

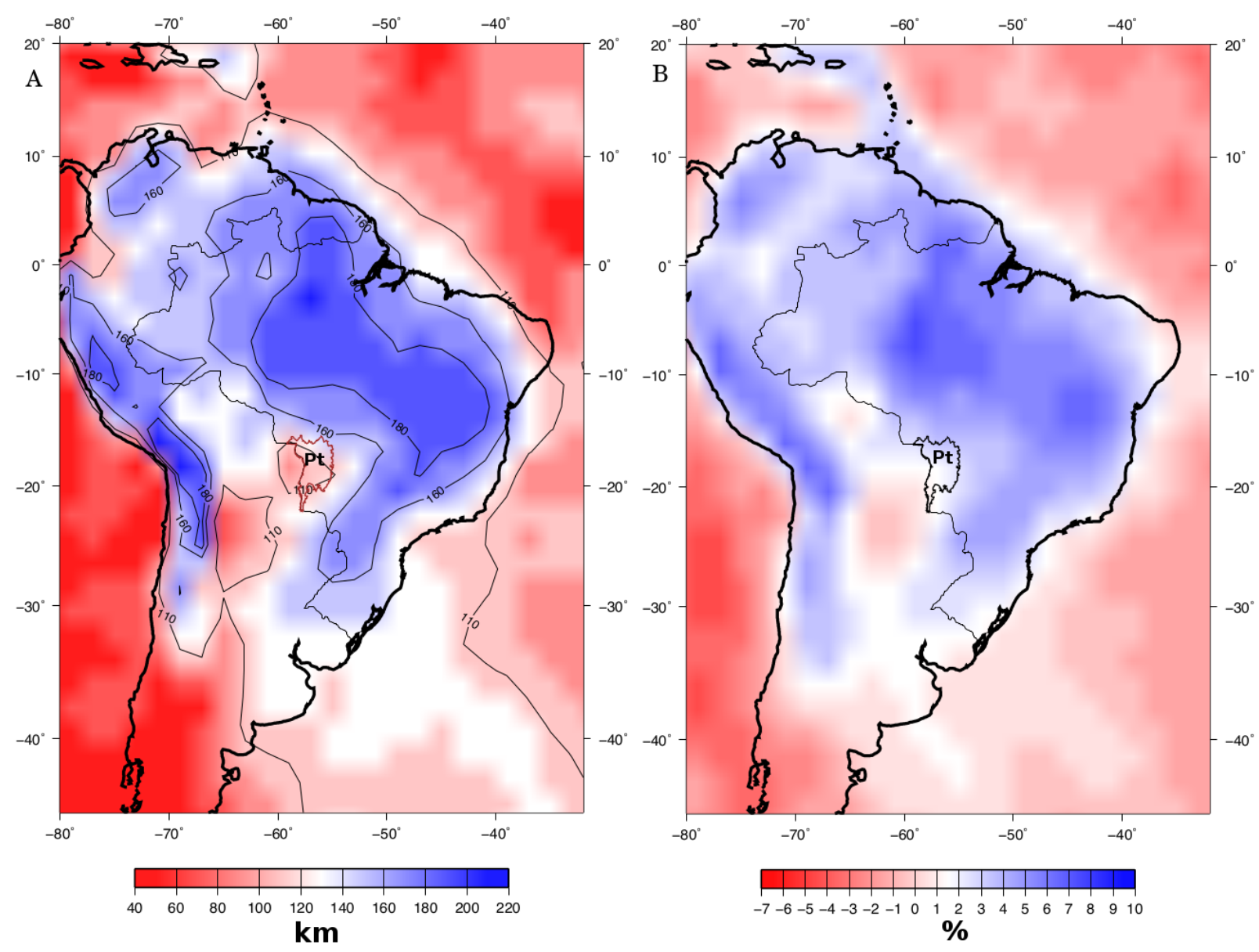

Figura 3.11: A: Profundidade da litosfera na BSP. B: Velocidade da onda SV em 150 km. Imagem retirada de CAM2016.

No trabalho de Feng et al. (2007) há uma perda por volta de 3\% na velocidade da onda SV em torno de $100 \mathrm{~km}$, em $150 \mathrm{~km}$ esse valor fica por volta de $5 \%$ mais baixo que o modelo IASP91, Figura (3.12). 


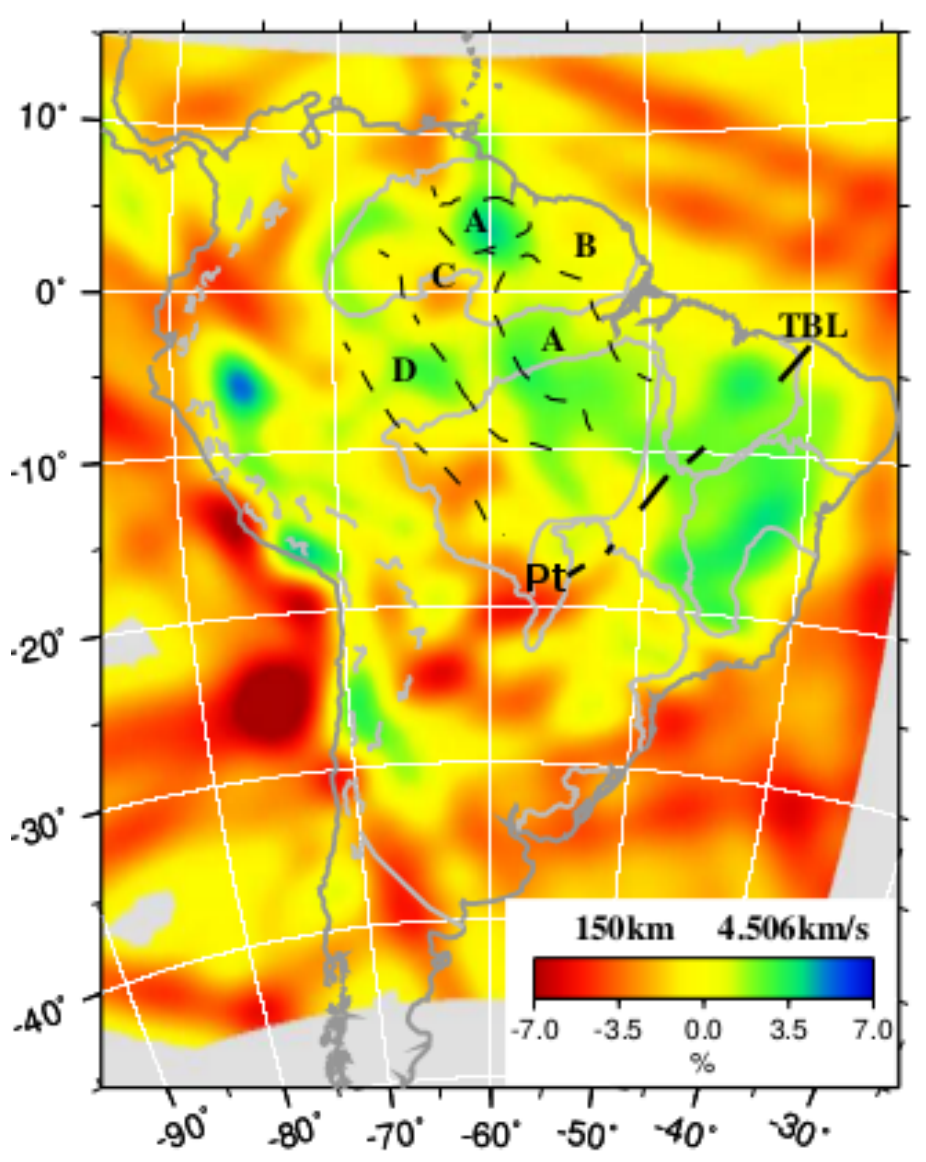

Figura 3.12: Anomalias da onda S em $150 \mathrm{~km}$ de profundidade, no qual se usou dispersão das ondas de superfície, imagem retirada de Feng et al. (2007). A região de anomalia negativa da bacia se situa entre $15^{\circ}$ a $20^{\circ} \mathrm{S}$ e a $55^{\circ}$ a $60^{\circ} \mathrm{W}$. TBL: Linamento Transbrasiliano.

Embora a velocidade em $150 \mathrm{~km}$ do Modelo CAM2016 não concorde com as nossas e com a de (Feng et al., 2007), deve-se se considerar que a BSP possui uma litosfera fina e a região de baixa velocidade está associado com o LAB, como fora proposto por (Assumpção et al., 2004). 
Capítulo 4

\section{Conclusões}

A instalação de estações temporárias pelo projeto Três bacias (Rede XC) propiciou uma melhor cobertura, se comparado com os demais trabalhos já feitos na BSP, permitindo mapear estruturas do manto superior com uma melhor resolução a partir uso da técnica de filtragem múltipla para ondas de superfície. Neste trabalho obtemos seis modelos de velocidade, sendo três deles para cada tipo de onda (Rayleigh e Love).

Dos seis modelos de velocidade apresentados, todos apresentam uma redução na velocidade, próxima a $90 \mathrm{~km}$. No entanto os modelos para SV são mais confiáveis, visto que apresentam uma maior quantidade de dados. Para SH houve somente um curva com período maior que 100 segundos, contudo os modelos I e II apresentaram um bom ajuste.

O método para obter a velocidade de grupo média do arranjo de estações não obteve exatidão para períodos maiores que 42 segundos. Isso pode ser justificado pela distribuição das estações.

Em nosso caso, os períodos mais baixos utilizados foram o do primeiro modo superior, no entanto, foram poucas curvas utilizadas, pois mensurá-lo não foi uma tarefa trivial. Outro fator importante é que por utilizar eventos de magnitude maiores do que 5,5, dois anos de análise é um período de tempo curto. Para obter períodos maiores são necessários eventos distantes e com grandes magnitudes, algo que foi buscado neste trabalho, contudo poucos eventos deste tipo foram captados.

Observando os trabalhos já realizados na Bacia Sedimentar do Pantanal, essa região de baixa velocidade observada, trata-se de um afinamento litosférico, corroborando para o soerguimento da astenosfera, que assim acarreta a elevação do fluxo de calor e mudanças na reologia da litosfera da BSP, conforme propôs Assumpção et al. (2004). 


\section{Referências Bibliográficas}

Assine M., Soares P., Quaternary of the Pantanal, west-central Brazil, Geologia USP. Série Científica, 2004, vol. 114, p. 23

Assine M. L., Merino E. R., Pupim F. N., Warren L. V., Guerreiro R. L., McGlue M. M., Geology and geomorphology of the Pantanal basin. In Dynamics of the Pantanal wetland in South America, Springer, Cham., 2015

Assumpção M., Feng M., Tassara A., Julià J., Models of crustal thickness for South America from seismic refraction, receiver functions and surface wave tomography, Tectonophysics, 2013, vol. 609, p. 82

Assumpção M., Sacek V., Intraplate seismicity and flexural stresses in Central Brazil, Geophysical Research Letters, 2013, vol. 40, p. 487

Assumpção M., Schimmel M., C E., Roberto Barbosa J., Rocha M., Barros L. V., Intraplate seismicity in SE Brazil: stress concentration in lithospheric thin spots, Geophysical Journal International, 2004, vol. 159, p. 390

Assumpção M., Suárez G., Source mechanisms of moderate size earthquakes and stress orientation in mid-plate South America, Geophys, 1988, vol. 92, p. 253

Cara M., Leveque J., Waveform inversion using secondary observables, Geophysical Research Letters, 1987, vol. 14, p. 1046

Christensen N. I., Mooney W. D., Seismic velocity structure and composition of the continental crust: A global view., Journal of Geophysical Research: Solid Earth, 1995, vol. 100 , p. 9761 
de Almeida T. I. R., Fernandes E., Mendes D., Branco F. C., Sígolo J. B., Distribuição espacial de diferentes classes de Lagoas no Pantanal da Nhecolândia, MS, a partir de dados vetoriais e SRTM: uma contribuição ao estudo de sua compartimentação e gênese, Geologia USP. Série Científica, 2007, vol. 7, p. 95

Debayle E., M S., Inversion of massive surface wave data sets: model construction and resolution assessment, Journal of Geophysical Research: Solid Earth, 2004, vol. 109

Debayle E., Y R., A global shear velocity model of the upper mantle from fundamental and higher Rayleigh mode measurements, Journal of Geophysical Research: Solid Earth, 2004, vol. 117

Debayle E., Y R., The thermal structure of the lithosphere from shear wave velocities, Earth and Planetary Science Letters, 2006, vol. 244, p. 285

Dias F. L., Assumpcão M., Facincani E. M., França G S Assine M. L., Paranhos Filho A. C., Gamarra R. M., The 2009 earthquake, magnitude mb 4.8, in the Pantanal Wetlands, west-central Brazil, Anais da Academia Brasileira de Ciências, 2016, vol. 88, p. 1253

Dziewonski A., Bloch S., Landisman M., A technique for analysis of transient seismic signals, Bull. Seism. Soc. Am., 1969, vol. 59, p. 427

Eaton D. W., Darbyshire F., Evans R. L., Grütter H., Jones A. G., Yuan X., The elusive lithosphere-asthenosphere boundary (LAB) beneath cratons, Lithos, 2009, vol. 354, p. 1

Facincani E. M., Assumpção M. S., Assine M. L., França G. L. S. A., Sismicidade da Bacia do Pantanal Mato-Grossense. In XIII Simpósio Nacional de Estudos Tectônicos (XIII SNET) , 2011

Feng M., Tomografia de ondas de superfície na América do Sul: inversão conjunta de velocidade de grupos e formas de ondas, São Paulo: IAG-USP, 2004, Tese de Doutorado, $142 \mathrm{p}$.

Feng M., Van der Lee S., Assumpção M., Upper mantle structure of South America from joint inversion of waveforms and fundamental mode group velocities of Rayleigh waves, Journal of Geophysical Research: Solid Earth, 2007 
Freedman R., Sears F., Young H., Zemansky M., Sears Zemansky Física universitaria: con física moderna/Física universitaria (No. 53). Addison-Wesley;., 2009

Goldstein P., Dodge D., Firpo M., Minner L., Lee W., Kanamori H., Jennings P., Kisslinger C., SAC2000: Signal processing and analysis tools for seismologists and engineers, The IASPEI International Handbook of Earthquake and Engineering Seismology, 2003, vol. 81, p. 1613

Herrin E., Goforth T., Phase-matched filters: Application to the study of Rayleigh waves, Bull. Seism. Soc. Am., 1977, vol. 67, p. 1259

Herrmann R. B., Ammon C. J., Computer programs in seismology - surface waves, receiver functions and crustal structure, The IASPEI International Handbook of Earthquake and Engineering Seismology, 2002

Ho T., K P., E D., A global horizontal shear velocity model of the upper mantle from multimode Love wave measurements,, Geophysical Journal International, 2016, vol. 207, p. 542

OpenCourseWare M., , 2008 Introduction to Seismology

Pasyanos M. E., A variable-resolution surface wave dispersion study of western Eurasia and North Africa, Journal of Geophysical Research, 2005, pp 276-277

Plomerová J., Kouba D., Babuska V., Mapping the lithosphere-asthenosphere boundary through changes in surface-wave anisotropy, Tectonophysics, 2002, vol. 358, p. 175

Pérez-Gussinyé M., Lowry A. R., Watts A. B., Effective elastic thickness of South America and its implications for intracontinental deformation, Geochemistry, Geophysics, Geosystems, 2007, p. 5

Radi Z., Yelles-Chaouche A., Corchete V., Guettouche S., Crust and upper mantle shear wave structure of Northeast Algeria from Rayleigh wave dispersion analysis, Physics of the Earth and Planetary Interiors, 2017, vol. 270, p. 84

Rivadeneyra-Vera J. C., Bianchi M. B., Assumpção M., Cedraz V., Julià J., Rodríguez M., Sánchez L., Sánchez G., Lopez-Murua L., Fernandez G., Fugarazzo R., An updated crustal thickness map of central South America based on receiver function measurements 
in the region of the Chaco, Pantanal and Paraná Basins, southwestern Brazil, Journal of Geophysical Research: Solid Earth, 2019

Ussami N., Shiraiwa S., Dominguez J. M. L., Basement reactivation in a sub-Andean foreland flexural bulge: The Pantanal wetland, SW Brazil, Tectonics, 1999, vol. 18, p. 34 
Apêndice 

Apêndice $A$

Estações Utilizadas Por Evento 
Tabela A.1 - Estações Utilizadas (Modo Fundamental, Rayleigh)

\begin{tabular}{|c|c|c|c|c|c|}
\hline $\mathrm{N}^{\circ}$ do Evento & Id & Redes & & & Epicentros \\
\hline- & - & $\mathrm{XC}$ & BL & BR & - \\
\hline 0 & coty & AMBA; ANTJ; BBLB; BBRB;BDQN; MURT; POCN; RVDE & AQDB; PP1B & SALV & Colômbia \\
\hline 1 & iacr & BBLB; BBRB; BDQN; CCRS; MURT; RPRD & AQDB; PP1B & SALV & Próximo à Costa Central Chile \\
\hline 2 & igyo & AMBA; ANTJ; BBLB; BBRB;BDQN; MURT; RPRD & AQDB; PP1B & - & Próximo à Costa Central Chile \\
\hline 3 & igzs & AMBA; ANTJ; BBLB; BBRB;BDQN; MURT; RPRD & AQDB; PP1B & SALV & Próximo à Costa Central Chile \\
\hline 4 & jdmf & ANTJ; BBLB; BBRB;BDQN; MURT; RPRD & AQDB; PP1B & SALV & Região Sul das Ilhas Sandwich \\
\hline 5 & lkex & ANTJ; BBLB; BBRB;BDQN; MURT; PANT; RPRD & AQDB; PP1B & SALV & Próximo à Costa Central Chile \\
\hline 6 & $\mathrm{mspc}$ & AMBA; ANTJ; BDQN; RPRD & PP1B & SALV & Próximo à Costa do Equador \\
\hline 7 & opoo & AMBA;BBLB; BBRB; BDQN; MURT & AQDB; PP1B & - & Norte do Oceano Atlântico \\
\hline 8 & puob & AMBA; ANTJ; BBLB; BBRB;BDQN; MURT; POCN & AQDB; PP1B & SALV & Central Peru \\
\hline 9 & ribw & AMBA; ANTJ; BBLB; BBRB; BDQN; MURT; RPRD & AQDB; PP1B & - & Região Sul das Ilhas Sandwich \\
\hline 10 & rpdi & AMBA; ANTJ; BBLB; BDQN; MURT; POCN & - & - & Próximo à Costa de Chiapas, México \\
\hline 11 & tvsu & AMBA;BBLB; BBRB; BDQN; CCRS; MURT; POCN; RPRD & AQDB; PP1B & SALV & Norte do Chile \\
\hline 12 & twrg & AMBA; ANTJ; BBLB; BBRB; BDQN & AQDB; PP1B & - & Região da Ilha Bouvet \\
\hline 13 & xkxm & AMBA; ANTJ; BBLB; BBRB; BDQN; MURT; RVDE & AQDB & SALV & Cordilheira Atlântico \\
\hline 14 & znwd & AMBA; ANTJ; BBLB; MURT & AQDB; PP1B & SALV & Norte do Chile \\
\hline 15 & aylz & AMBA; ANTJ; MURT; RPRD; RVDE & AQDB; PP1B & - & Próximo a Costa do Peru \\
\hline 16 & bqpy & BDQN; RVDE & AQDB; PP1B & SALV & Norte do Chile \\
\hline 17 & aqre & AMBA; ANTJ; BBLB; BBRB; BDQN; CCRS; MURT; POCN; RVDE & AQDB; PP1B & SALV & Norte de Honduras \\
\hline 18 & gzrg & AMBA; ANTJ; BBRB; BDQN; RPRD; RVDE & AQDB; PP1B & SALV & Próximo à Costa Central Chile \\
\hline 19 & pvjd & AMBA; MURT; RPRD; RVDE & AQDB; PP1B & SALV & Região Sul das Ilhas Sandwich \\
\hline 20 & rncq & RPRD & AQDB & SALV & Equador \\
\hline 21 & tabs & AMBA; BDQN; MURT; RPRD & AQDB & SALV & Minahassa Península, Sulawesi \\
\hline 22 & tptu & AMBA; BDQN; MURT; & AQDB & SALV & Região do Haiti \\
\hline 23 & $\mathrm{xcsc}$ & ANTJ; BBLB; BBRB;BDQN; MURT; RVDE & AQDB & - & Distante da Costa Central América \\
\hline
\end{tabular}

Tabela A.2 - Estações Utilizadas (Primeiro Modo Superior, Rayleigh)

\begin{tabular}{|c|c|c|c|c|c|}
\hline $\mathbf{N}^{\mathbf{o}}$ do Evento & Id & \multicolumn{2}{|c|}{ Redes } & Epicentros \\
\hline- & - & XC & BL & BR & - \\
\hline 2 & igyo & AMBA; ANTJ; BBRB;BDQN; MURT; RPRD & AQDB; PP1B & - & Próximo à Costa Central Chile \\
\hline 3 & igzs & AMBA; ANTJ; BBLB; BBRB;BDQN; MURT; RPRD & AQDB & - & Próximo à Costa Central Chile \\
\hline 5 & lkex & AMBA; BBRB;BDQN; MURT & AQDB; PP1B & - & Próximo à Costa Central Chile \\
\hline 8 & puob & ANTJ; BBLB; BBRB;BDQN; POCN & AQDB & SALV & Central Peru \\
\hline 14 & znwd & AMBA; ANTJ; BBLB; MURT & PP1B & - & Norte do Chile \\
\hline
\end{tabular}

Tabela A.3 - Estações Utilizadas (Modo Fundamental, Love)

\begin{tabular}{|c|c|c|c|c|c|}
\hline No do Evento & Id & \multicolumn{2}{|c|}{ Redes } & Epicentros \\
\hline- & - & XC & PP & BR & - \\
\hline 6 & mspc & AMBA; ANTJ; BDQN; RPRD & AQDV & Próximo à Costa do Equador \\
\hline 7 & opoo & BBLB; BBRB; BDQN; MURT & AQDB & - & Região Sul das Ilhas Sandwich \\
\hline 9 & ribw & AMBA; ANTJ; BDQN; RPRD & AQDB & - & Próximo à Costa de Chiapas, México \\
\hline 10 & rpdi & AMBA; ANTJ; BDQN; RPRD & AQDB; PP1B & SALV & Região Sul das Ilhas Sandwich \\
\hline 18 & gzrg & AMBA; ANTJ; BBRB; BDQN; MURT; RPRD; RVDE & AQDB; PP1B & SALV & Próximo à Costa Central Chile \\
\hline 19 & pvjd & AMBA; MURT; RPRD; RVDE & AQDB & SALV & Equador \\
\hline 20 & rncq & AMBA; RPRD & AQDB & - & Minahassa Península, Sulawesi \\
\hline 21 & tabs & AMBA; BDQN; MURT; RPRD & &
\end{tabular}

